\title{
Internal structure of the San Jacinto fault zone in the trifurcation area southeast of Anza, California, from data of dense seismic arrays
}

\author{
L. Qin, ${ }^{1}$ Y. Ben-Zion, ${ }^{1}$ H. Qiu, ${ }^{1}$ P.-E. Share, ${ }^{1}$ Z.E. Ross ${ }^{2}$ and F.L. Vernon ${ }^{3}$ \\ ${ }^{1}$ Department of Earth Sciences, University of Southern California, Los Angeles, CA 90089, USA. E-mail: qinl@usc.edu \\ ${ }^{2}$ Seismological Laboratory, California Institute of Technology, Pasadena, CA 91125, USA \\ ${ }^{3}$ Scripps Institution of Oceanography, University of California San Diego, LaJolla, CA 92093, USA
}

Accepted 2017 December 15. Received 2017 November 26; in original form 2017 May 29

\begin{abstract}
S U M M A R Y
We image the internal structure of the San Jacinto fault zone (SJFZ) in the trifurcation area southeast of Anza, California, with seismic records from dense linear and rectangular arrays. The examined data include recordings from more than 20000 local earthquakes and nine teleseismic events. Automatic detection algorithms and visual inspection are used to identify $P$ and $S$ body waves, along with $P$ - and $S$-types fault zone trapped waves (FZTW). The location at depth of the main branch of the SJFZ, the Clark fault, is identified from systematic waveform changes across lines of sensors within the dense rectangular array. Delay times of $P$ arrivals from teleseismic and local events indicate damage asymmetry across the fault, with higher damage to the NE, producing a local reversal of the velocity contrast in the shallow crust with respect to the large-scale structure. A portion of the damage zone between the main fault and a second mapped surface trace to the NE generates $P$ - and $S$-types FZTW. Inversions of high-quality $S$-type FZTW indicate that the most likely parameters of the trapping structure are width of $\sim 70 \mathrm{~m}, S$-wave velocity reduction of 60 per cent, $Q$ value of 60 and depth of $\sim 2 \mathrm{~km}$. The local reversal of the shallow velocity contrast across the fault with respect to large-scale structure is consistent with preferred propagation of earthquake ruptures in the area to the NW.
\end{abstract}

Key words: Body waves; Earthquake dynamics; Guided waves; Interface waves; Rheology and friction of fault zones; Continental tectonics: strike-slip and transform.

\section{INTRODUCTION}

Large fault zone (FZ) structures separate different crustal blocks and have hierarchical damage zones resulting from long-term evolution and recurring earthquake ruptures (e.g. Ben-Zion \& Sammis 2003). High-resolution imaging of FZ structures can provide important information on a wide range of topics including likely properties of earthquake ruptures, stress and strength of the crust, development of improved seismic catalogues and crustal hydrology. In particular, asymmetric rock damage across the main fault can reflect statistically preferred propagation direction of earthquake ruptures in the area (Ben-Zion \& Shi 2005; Lewis et al. 2005; Dor et al. 2006). This may result from ruptures that are localized along a deep bimaterial interface in the FZ structure (e.g. Andrews \& Ben-Zion 1997; BenZion 2001; Brietzke \& Ben-Zion 2006). Rock damage is expected to be pronounced in the top few kilometres of the crust, and to exist primarily on the side with faster seismic velocity at depth (e.g. Ben-Zion \& Shi 2005; Xu \& Ben-Zion 2017). Such rock damage asymmetry would generate a local reversal of the velocity contrast across the fault in the shallow crust compared with the large-scale contrast.

The $230 \mathrm{~km}$ long San Jacinto fault zone (SJFZ) is the most seismically active component of the plate boundary system in Southern California over the last several decades (Hauksson et al. 2012), and is subparallel to the southern San Andreas fault to the NE and the Elsinore fault to the SW (Fig. 1a). In the last few years, data recorded by the regional seismic networks and local arrays crossing the SJFZ at several locations were used to obtain earthquakeand noise-based tomographic images for the region with nominal resolution of 1-2 km (e.g. Allam \& Ben-Zion 2012; Allam et al. 2014; Zigone et al. 2015). These studies were accompanied by finer scale imaging of fault bimaterial interfaces and damage zones (order $100 \mathrm{~m}$ wide) at several locations (Yang et al. 2014; Qiu et al. 2017; Share et al. 2017), along with anisotropy within and around the fault ( $\mathrm{Li}$ et al. 2015). In this study, we provide detailed information on the internal structure of the SJFZ at the Sage Brush (SGB) site SE of Anza, California, using seismic data recorded by linear and dense rectangular arrays (Fig. 1c). Our main 

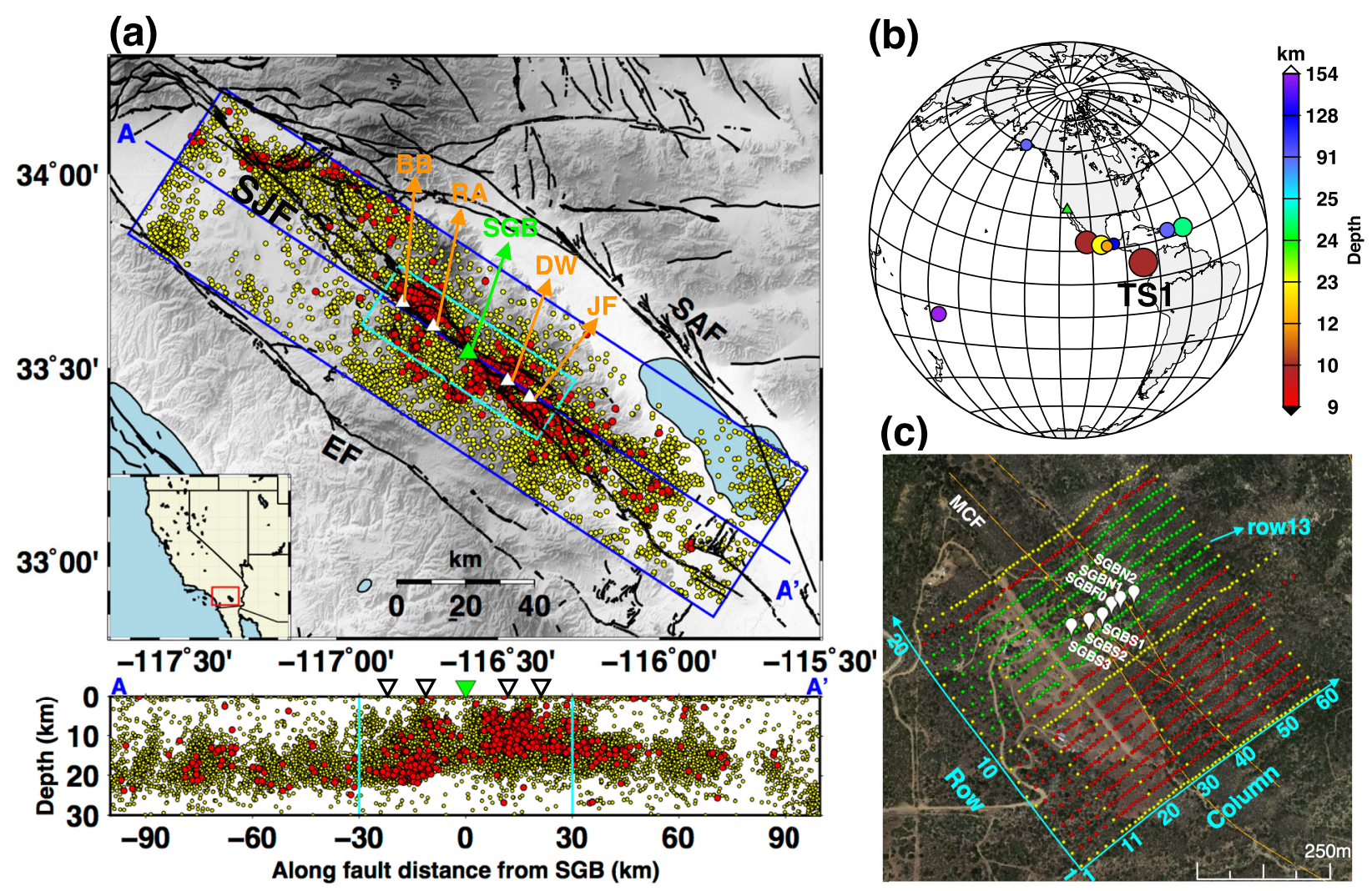

Figure 1. (a) Location map of the SJFZ and the $\sim 20000$ local events used in the study. Fault traces are shown with black lines. The green triangle marks the SGB site (all future plots use the same symbol for SGB site unless otherwise stated), and the four white triangles are four other linear arrays straddling the Clark Fault (BB, RA, DW and JF from north to south). SAF and EF denote the San Andreas and Elsinore faults. Yellow and red circles represent events recorded by the linear SGB and dense rectangular arrays, respectively. The long blue line (AA') indicates the geological strike direction of the Clark fault. The blue $(200 \mathrm{~km} \times 50 \mathrm{~km})$ and cyan $(60 \mathrm{~km} \times 20 \mathrm{~km})$ boxes, centred at the SGB site, include events used for the FZTW and delay time analysis, respectively. The lower panel is the depth profile of all events projected to the cross-section $\mathrm{AA}^{\prime}$. The two cyan lines correspond to boundaries of the cyan box in the top panel and the five triangles correspond to the five linear arrays. (b) Locations of nine teleseismic events with high-quality first arrivals. Colour represents depth and circle size represents magnitude. TS1 is the example event in Fig. 6(a). See Table 1 for additional information on the teleseismic events. (c) Sensors of the linear SGB array (white balloons with labels) and dense rectangular array (dots). Orange lines indicate fault surface traces including the main Clark fault (MCF). The row and column numbers of the dense array start from the SW corner and increase toward the NW and NE (cyan arrows), respectively. Row 13 of the dense array which is the closest row to the linear SGB array is labeled. Data of the green sensors (rows 12-18) are stacked to identify $S$-type FZTW in the dense array. Some sensors are coloured yellow for easier identification of row and column numbers.

goals are to find the seismogenic location of the main branch of the SJFZ in the region, the Clark fault, and to analyse the symmetry properties of the FZ damage with respect to the Clark fault. The imaged SGB site is in the complex trifurcation area of the SJFZ, which is highly active seismically with ongoing small and moderate events (e.g. Kurzon et al. 2014; Ross et al. 2017). The detailed seismic imaging at this site complements similar studies done with linear arrays across the SJFZ at other locations marked in Fig. 2.

In the next section, we describe the seismic data used in this work. In Section 3, we first examine data recorded by the dense rectangular array for systematic waveform changes to identify the location of the main seismogenic fault. Then, we analyse delay times of $P$ waves generated by teleseismic and local events to estimate variations of slowness across the FZ structure. In addition, we use automatic detection algorithms to find $P$ - and $S$-types fault zone trapped wave (FZTW), and invert high-quality $S$-type trapped waves for parameters of the FZ trapping structure. The results show systematic rock damage asymmetry across the fault, producing locally lower velocities in the shallow structure on the crustal block with faster seismic velocity at depth. The results are summarized and discussed in Section 4 of the paper.

\section{DATA}

The analysed data are recorded by two seismic arrays at the Sage Brush site: a linear SGB array and a dense rectangular array (Fig. 1c). Both arrays straddle the Clark branch of the SJFZ southeast of Anza, California, and the linear array overlaps with columns 26-40 of row 13 of the dense rectangular array. The linear SGB array has six 3-component accelerometers recording at $200 \mathrm{~Hz}$ with instrument spacing of about $25 \mathrm{~m}$, and is part of a larger PASSCAL deployment within and around the SJFZ that started in 2010 (Vernon \& Ben-Zion 2010). The rectangular array consists of 1108 vertical $10 \mathrm{~Hz} Z \mathrm{~L}$ and geophones and it operated with a sampling rate of $500 \mathrm{~Hz}$ between 2014 May 7 and June 13 (Ben-Zion et al. 2015). This array covers an area of $\sim 650 \mathrm{~m} \times 650 \mathrm{~m}$ with $\sim 55$ columns in the fault-normal direction (SW-NE) with instrument spacing of $10 \mathrm{~m}$, and 20 rows in the fault-parallel direction (SE-NW) with $30 \mathrm{~m}$ instrument spacing. 


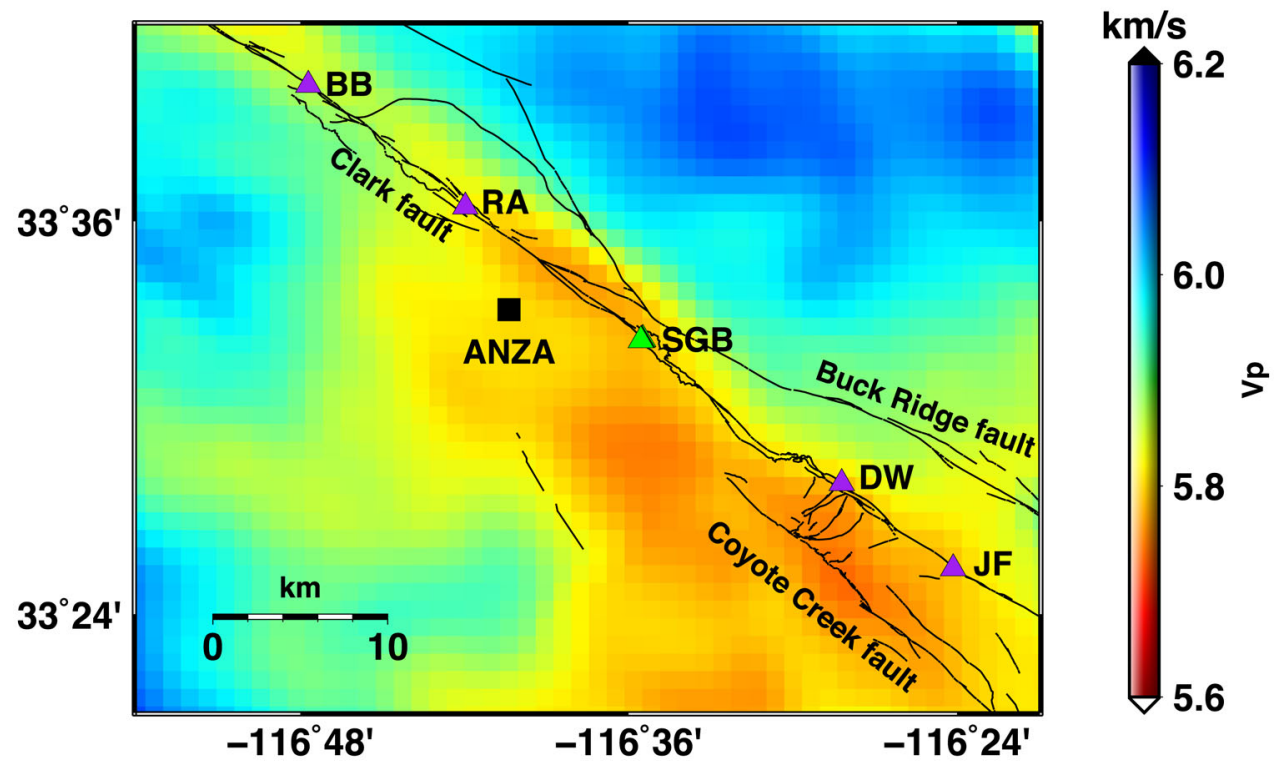

Figure 2. Average $P$-wave velocity over the depth range 1-10 km based on the tomography results of Allam \& Ben-Zion (2012). The town of Anza and several linear arrays are shown by a square and triangles, respectively. Black lines represent fault surface traces. The SJFZ branches into three faults (Buck Ridge, Clark and Coyote Creek) near the SGB site.

Table 1. Selected teleseismic events.

\begin{tabular}{|c|c|c|c|c|}
\hline Event ID & Origin time & $\begin{array}{l}\text { Latitude (degree), Longitude } \\
\text { (degree), Depth }(\mathrm{km})\end{array}$ & Magnitude & $\begin{array}{c}\text { Great circle } \\
\text { distance }(\mathrm{km})\end{array}$ \\
\hline 37199173 & $2014 / 05 / 09,10: 32: 18.700$ & $-18.9,-175.6,153$ & 5.8 & 8553 \\
\hline 37199493 & 2014/05/10, 07:36:01.400 & $17.2,-100.8,23$ & 6 & 2408 \\
\hline 37200141 (TS1) & $2014 / 05 / 13,06: 35: 24.300$ & $7.2,-82.3,10$ & 6.5 & 4581 \\
\hline 37201893 & 2014/05/16, 11:01:42.900 & $17.1,-60.4,25$ & 6 & 5864 \\
\hline 37202405 & $2014 / 05 / 21,10: 06: 14.900$ & $17.2,-94.9,127$ & 5.6 & 2829 \\
\hline 37203109 & $2014 / 05 / 31,11: 53: 48.100$ & $18.9,-107.4,10$ & 6.2 & 1874 \\
\hline
\end{tabular}

For the SGB array, we use local seismic data recorded over a three-year period (2012-2014), during which $>20000$ local events were detected by the ANZA network (Fig. 1a). For the dense rectangular array, local and teleseismic data are used together during the $\sim 1$-month deployment period. We analyse nine teleseismic events with magnitude $M>5.5$ (Table 1) from the Southern California Earthquake Data Center (SCEDC 2013), and $\sim 1000$ local events from a local catalogue detected by Ben-Zion et al. (2015). Fig. 1 shows the study area, seismic stations and event information. The large blue box in Fig. 1(a) $(200 \mathrm{~km}$ in the along strike and $50 \mathrm{~km}$ in the fault-normal directions) marks the area used to search for events generating FZTW. The small cyan box includes events used for delay time analysis of $P$ waves. The nine teleseismic events in Fig. 1(b) are selected because they generate clear first $P$ arrivals and are also used for delay time analysis.

\section{ANALYSIS}

The regional $P$-wave velocity model from Allam \& Ben-Zion (2012) shows that within the study area, the mapped surface trace of the Clark fault separates faster material in the northeast from slower rocks to the southwest (Fig. 2). However, the location of the seismogenic fault at depth and other details of the internal FZ structure are unresolved by the regional tomographic images. To clarify the location of the main seismogenic fault and properties of the damage FZ structure, we apply several types of analysis at different scales. These include searching the waveforms for systematic changes at given instrument locations, analysis of delay times of $\mathrm{P}$ waves generated by teleseismic and local events and analysis of $S$ - and $P$-types FZTW.

\subsection{Waveform changes}

\subsubsection{Methodology}

Ben-Zion (1989, 1998) and Ben-Zion \& Aki (1990) showed with model calculations that lateral variations of seismic properties across and within FZ affect the traveltime, wave amplitude, spectral content and motion polarities. Because of the FZ heterogeneity in the study area, substantial variations in waveform character and phases are expected within the arrays. These features are analysed below in detail to resolve the location of the main fault separating different crustal blocks at the SGB site. We apply a $0.5-20 \mathrm{~Hz}$ bandpass filter to all waveforms and examine the data visually for row 13 to find clear waveform changes in the fault-normal direction generated by many events. Then, we check the waveforms from all other rows inside the dense rectangular array, and track the location 


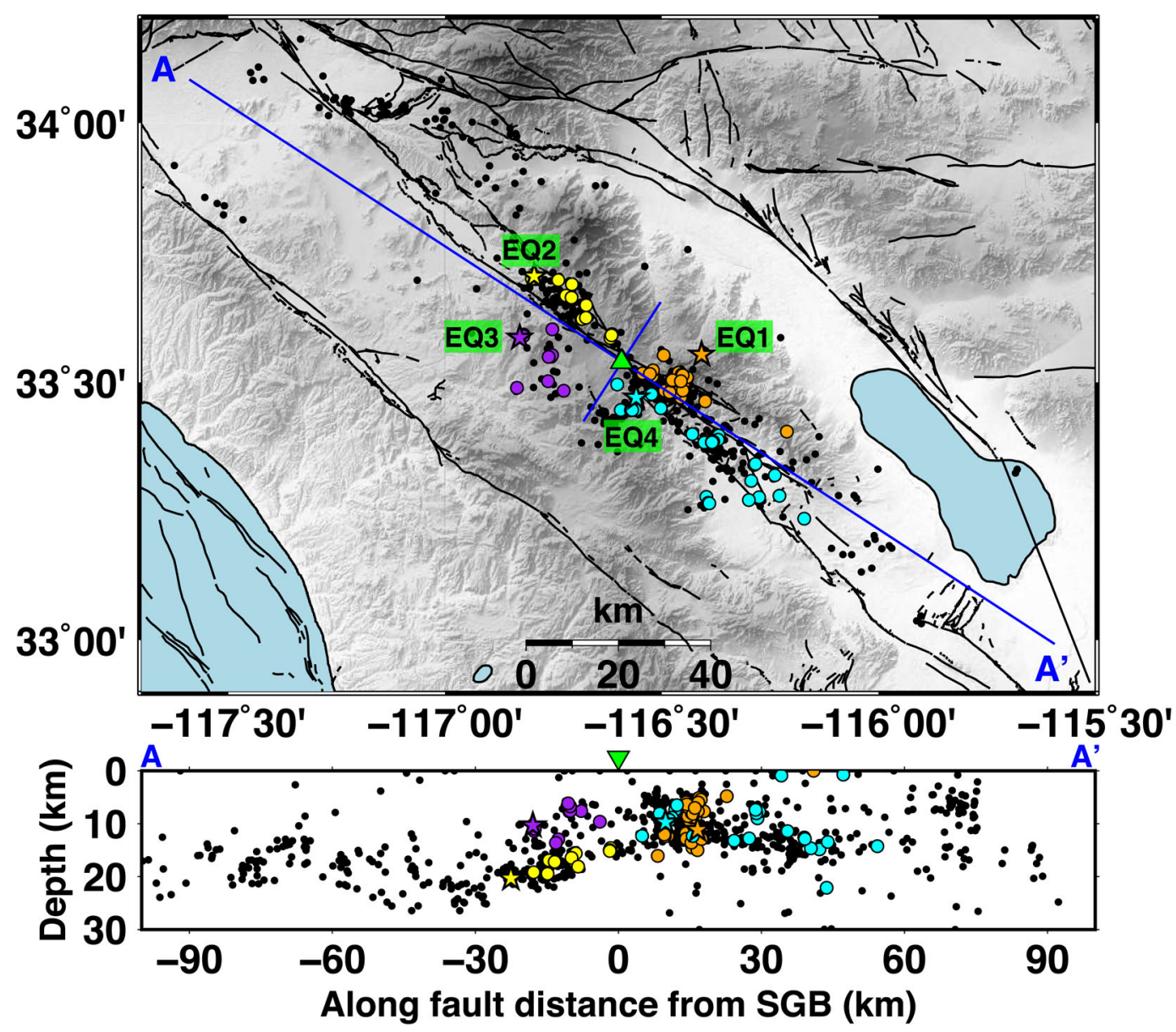

Figure 3. Location map of events (black dots) used to analyse waveform changes across the array. The long blue line (AA') is the same as in Fig. 1(a) and the short blue line perpendicular to $\mathrm{AA}^{\prime}$ is centred at the SGB site. The two lines separate the area into four quadrants with events colored by orange, yellow, purple and cyan showing clear waveform changes in row 13 of the dense array. The stars mark the four example events (EQ1 4) from the four quadrants. The lower panel is the depth profile projected to the cross-section $\mathrm{AA}^{\prime}$.

of the waveform changes within each row to find the primary fault location.

\subsubsection{Results}

Fig. 3 shows the locations of events generating clear and consistent waveform changes along row 13 of the dense rectangular array, identified from visual examination. The area is separated into four quadrants by the fault-parallel and fault-normal directions of the Clark fault at SGB. Fig. 4 displays waveforms of four representative events from the different quadrants recorded by row 13 . The waveform shapes generated by the four examples, and other earthquakes in the different quadrants, have some differences related to event locations and other factors such as focal mechanisms. Nevertheless, we observe a clear transition in the character of the waveforms at column 32 marked by the dashed red line. To see if this is persistent along strike, we examine data recorded by other rows of the dense rectangular array. The results indicate clear waveform changes at columns 28-32 of the dense rectangular array (this zone is marked in the final Fig. 15). As an example, Fig. 5 shows waveforms of EQ3 recorded by three other rows, with clear similar waveform changes at columns 29, 30 and 32 for rows 01, 10 and 19, respectively. We conclude that the seismogenic fault at depth is beneath columns $28-32$ of the dense array.

\subsection{Delay time analysis of teleseismic arrivals}

\subsubsection{Methodology}

Teleseismic arrivals sample the structure underneath the array with a nearly vertical incident angle and lower frequency content than the local seismic waves. Ozakin et al. (2012) analysed teleseismic arrival time differences at stations across the North Anatolian fault; Qiu et al. (2017) and Share et al. (2017) applied similar analyses, respectively, to the JF and $\mathrm{BB}$ arrays (Fig. 2). The clear direct $P$ waves from teleseismic events recorded by the long across fault lines of the dense array can be used to analyse the local velocity structure. This is done here with a similar analysis as Qiu et al. (2017), with the main difference that we use the southwesternmost station in a row as the reference. First, the observed delay time $\left(t_{i j \text { obs }}\right)$ from event $i$ at station $j$ in a given row is obtained using cross-correlation between the $j$ th trace and the template trace, that is, the record from the reference station. Then, we use the TauP toolkit (Crotwell et al. 1999) and IASP91 velocity model to calculate the predicted traveltime. Since this does not account for the local velocity structure, the traveltime difference from the reference station due to the station-event geometry $\left(t_{i j, \text { geo }}\right)$ is equal to the predicted traveltime difference between each station and the reference station. In addition, the traveltime difference caused by the station topography $\left(t_{j, \text { elv }}\right)$ is calculated by $\left(d_{j}-d_{\text {ref }}\right) / v_{\text {ref }}$, where $d_{j}$ and $d_{\text {ref }}$ 
(a)

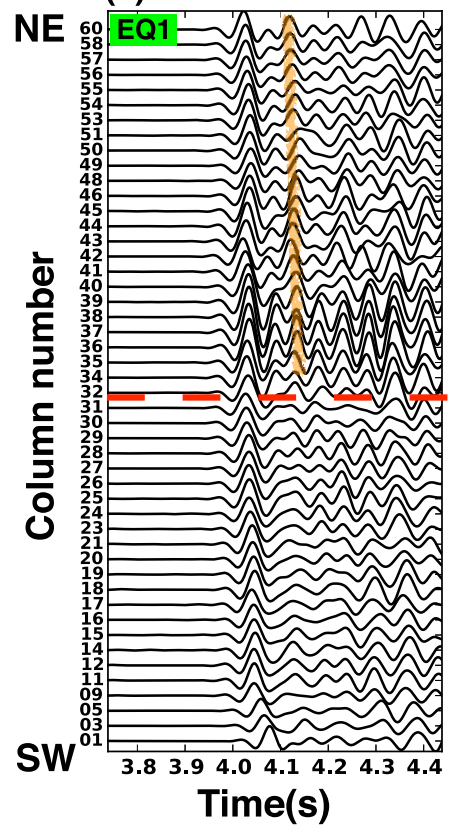

(b)

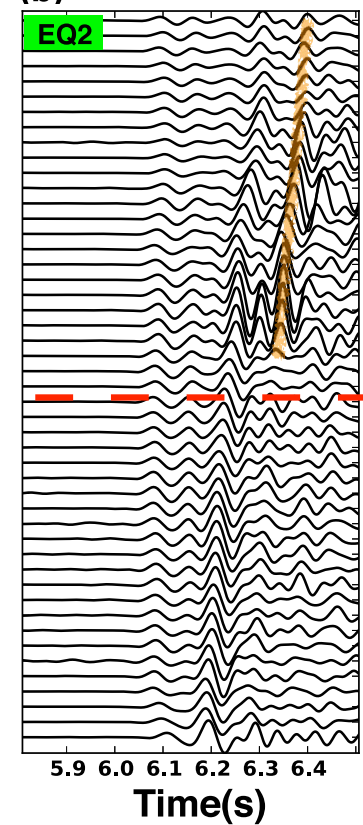

(c)

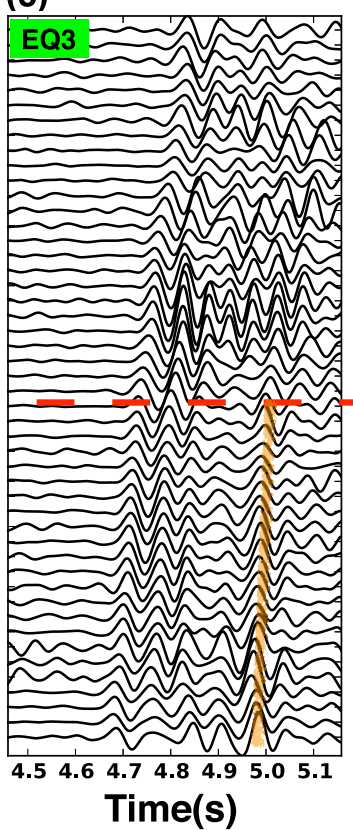

(d)

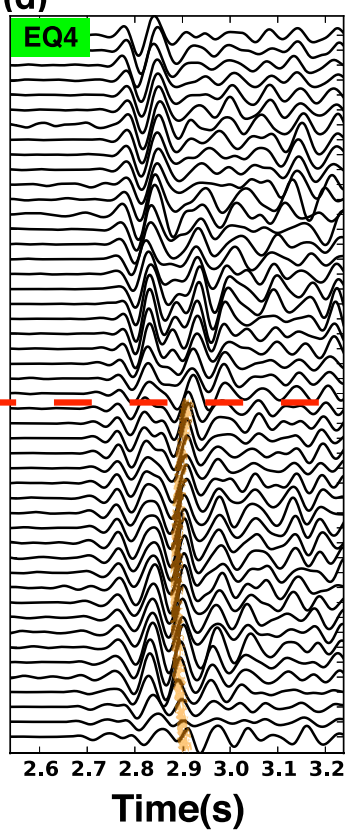

Figure 4. Waveforms $(0.5-20 \mathrm{~Hz}$ ) of four example events (stars in Fig. 3) recorded by row 13. Horizontal axis is the time relative to the origin time (all future plots use the same convention unless otherwise stated). The red dashed line, corresponding to column 32, indicates the location with clear waveform changes. The light orange lines mark phases that only exist on one side of the fault.

(a)

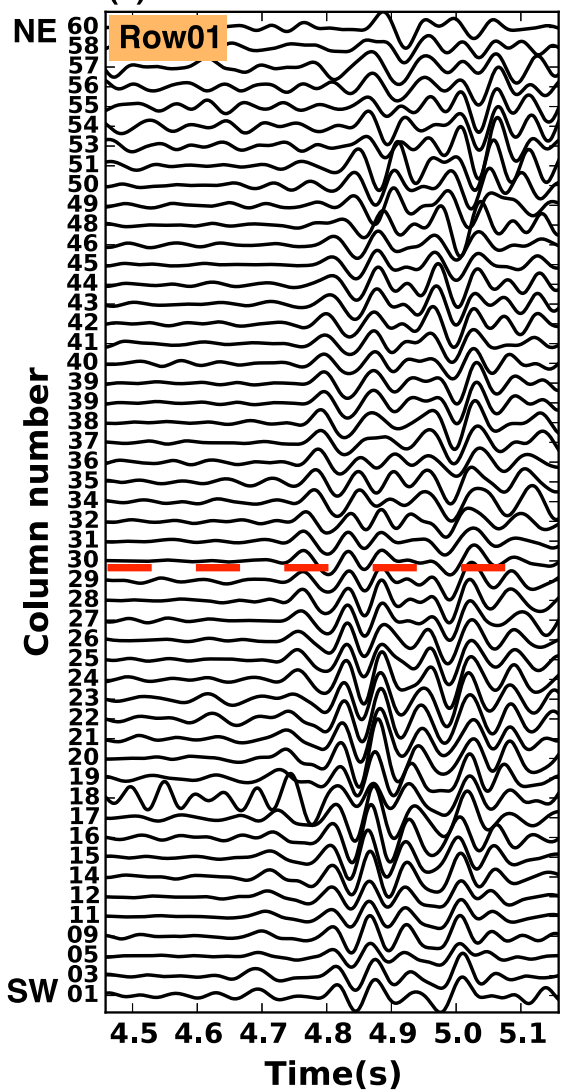

(b)

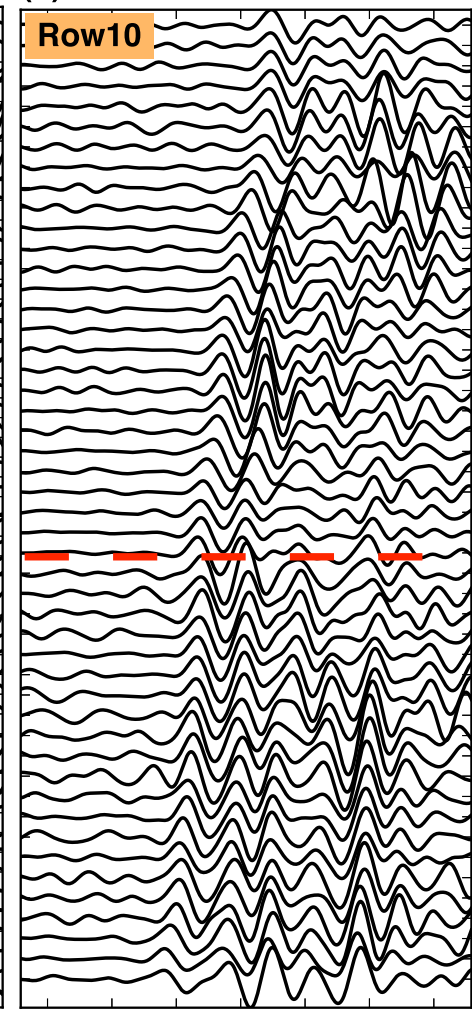

4.54 .64 .74 .84 .95 .05 .1 Time(s) (c)

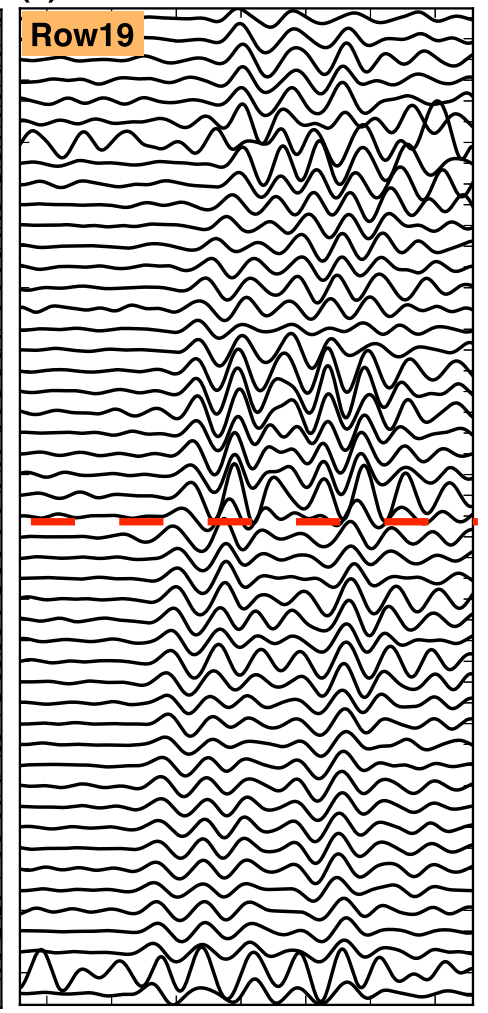

Time(s)

Figure 5. Waveforms $(0.5-20 \mathrm{~Hz})$ of event EQ3 recorded by (a) row 01 , (b) row 10 and (c) row 19. The red dashed lines indicate locations of clear waveform changes. 
(a)

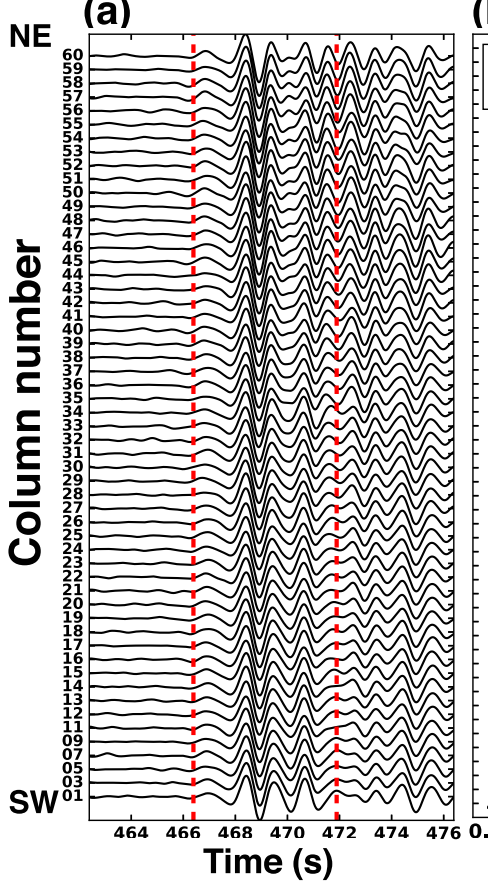

(b)

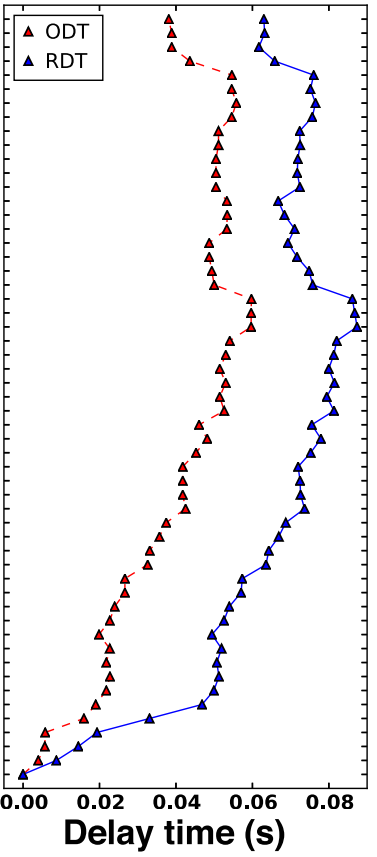

(c)

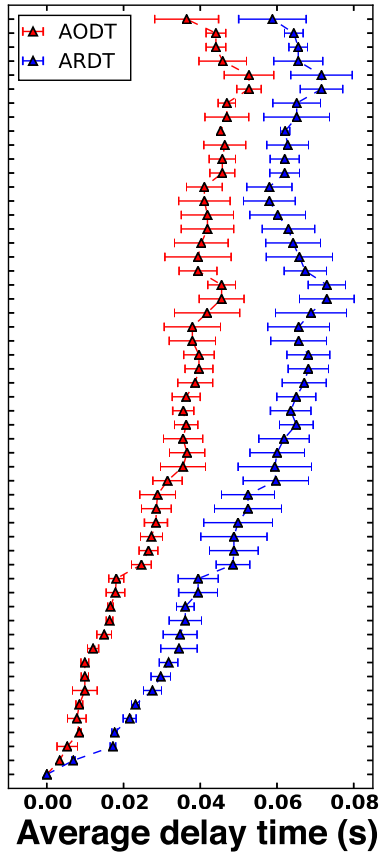

(d)

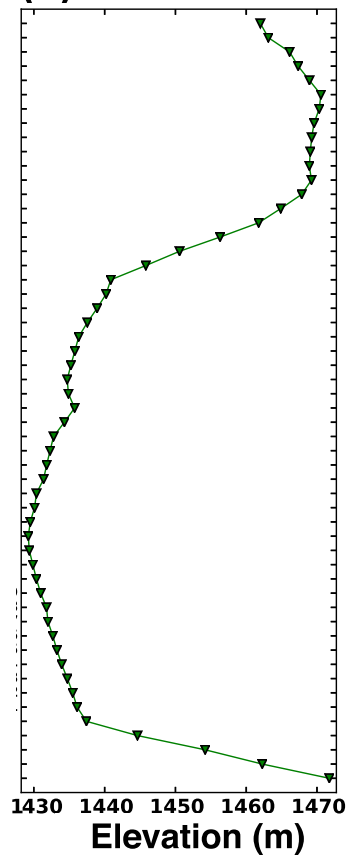

Figure 6. Delay time analysis results from teleseismic events. (a) Waveforms $(0.1-1.0 \mathrm{~Hz})$ of TS1 (Fig. 1b) recorded by row 13 . The red dashed lines indicate the $5.5 \mathrm{~s}$ time window for the cross-correlation. (b) Results from event TS1: observed delay time (ODT, red triangles) obtained by cross-correlation and relative delay time (RDT, blue triangles) after event-station geometry and station elevation corrections. (c) Average observed delay time (AODT, red triangles) and average relative delay time (ARDT, blue triangles) from all the nine teleseismic events. The error bar is one standard deviation. (d) Station elevation profile of row 13 .

are the elevations of the analysed and reference stations, and $v_{\text {ref }}$ is the average velocity of the surface layer. The relative delay time $\left(t_{i j}\right)$ from event $i$ at station $j$ with respect to the reference station, resulting from the local lateral variations across the fault, can be written as $t_{i j}=t_{i j \text {,obs }}-t_{i j, \text { geo }}-t_{j \text {,elv }}$. Considering the small aperture of the array relative to the event-station distance, the ray path difference between different stations stems primarily from the local structure. Thus, the observed delay time corrected by the geometry and elevation difference contains information of the local structure beneath the array. In a final analysis step, we average the observed and relative delay time from all the teleseismic events.

\subsubsection{Results}

We apply a $0.1-1.0 \mathrm{~Hz}$ bandpass filter to waveforms of teleseismic events with $M>5.5$ that occurred during the dense rectangular array deployment and discard events without clear first $P$ phases. We end up with nine teleseismic events with high-quality waveforms (Fig. 1b and Table 1). We analyse data recorded by row 13 of the dense array, choose the SW-most station as the reference, and crosscorrelate waveforms of each station with those of the reference station in a $5.5 \mathrm{~s}$ time window around the first arrival. This gives observed delay times, which are then corrected by the event-station geometry and station elevation difference to get the relative delay times. For average velocity of the surface layer, we use $v_{\text {ref }}=$ $2.0 \mathrm{~km} \mathrm{~s}^{-1}$, which is similar to the value used by Qiu et al. (2017).

Fig. 6(a) provides example waveforms from event TS1 (Fig. 1b) that change from SW to NE; the changes are smoother compared to those produced by the local events (Figs 4 and 5) because of the lower frequency content. The observed delay times obtained from cross-correlation (Fig. 6b, red triangles) suggest that locally, the NE side of the fault is slower than the SW side. The relative delay times (Fig. 6b, blue triangles) obtained after event-station geometry and station elevation corrections with a reference velocity of $2.0 \mathrm{~km} \mathrm{~s}^{-1}$ show a similar pattern. These results point to a local reversal of the velocity structure from that associated with (Fig. 2) the regional tomography of Allam \& Ben-Zion (2012). The average delay times (Fig. 6c) follow a similar pattern as that from a single event (Fig. 6b). The small error bars imply that the delay time patterns are independent of the event locations, and therefore represent the local velocity structure. The relative delay times correlate with the station elevations (Fig. 6d); the elevation difference can produce traveltime difference as large as $\sim 0.02 \mathrm{~s}$, while the maximum observed delay time is $\sim 0.04 \mathrm{~s}$. However, this does not affect the general conclusion on the local reversal of the velocity structure, which is observed also in the region with little topography.

\subsection{Delay time analysis of local direct $P$ waves}

\subsubsection{Methodology}

For the analysis of local direct $P$ waves, we follow the procedure of Qiu et al. (2017) and Share et al. (2017). The first step is to pick $P$-wave arrival times with an automatic algorithm (Ross \& Ben-Zion 2014; Ross et al. 2016). Then, we calculate the theoretical $P$-wave traveltime and along-path distance using an average 1-D velocity model based on the 3-D tomographic results of Allam \& Ben-Zion (2012). The slowness is equal to the ratio between the observed $P$-wave traveltime and the along-path distance (the slowness from deeper events is generally smaller, since it includes more information from the deeper structure). To obtain the 
(a)

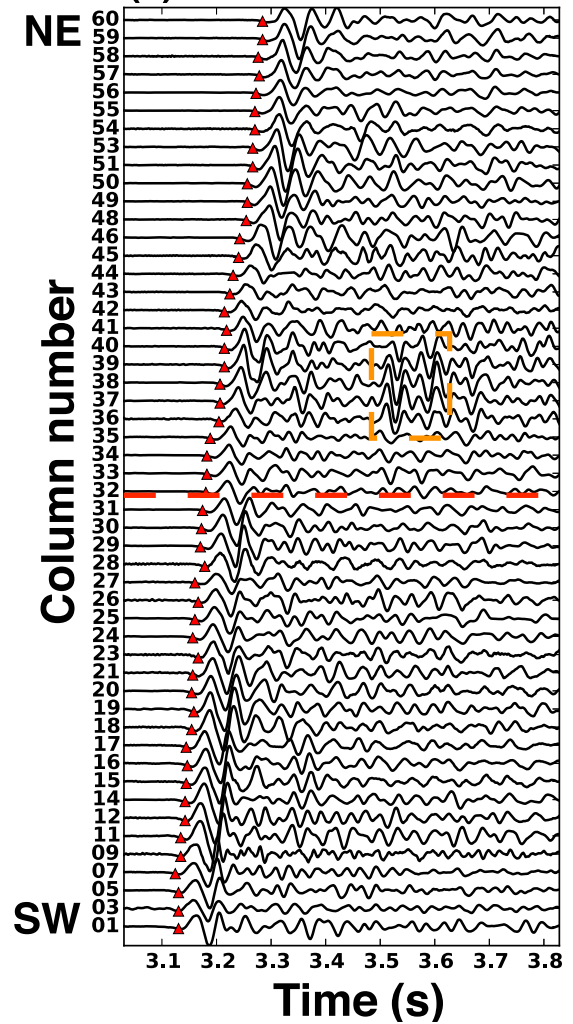

(b)

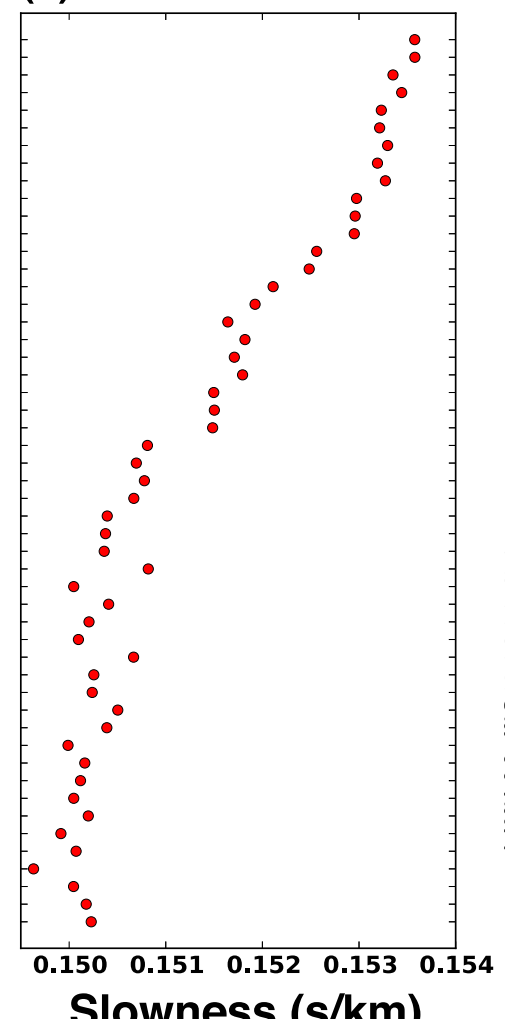

(c)

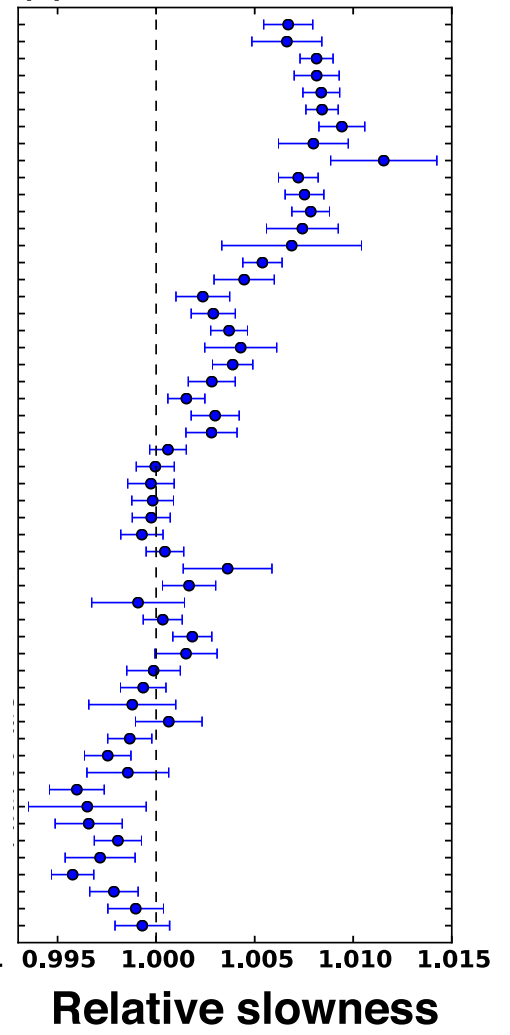

(d) Histogram of SGBS2

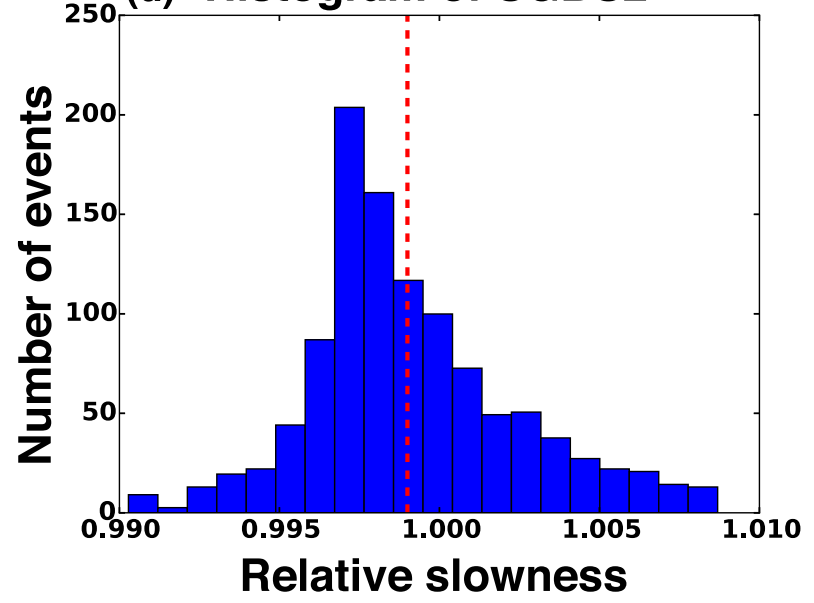

(e)

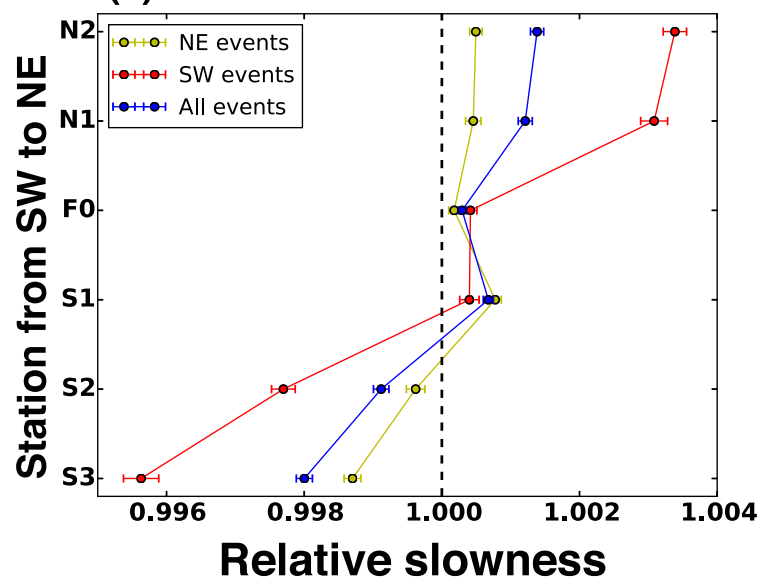

Figure 7. Delay time analysis results of data from the dense (a)-(c) and linear SGB (d)-(e) arrays. (a) Waveforms ( $0.5-20 \mathrm{~Hz})$ of an event recorded by row 13 of the dense array. The red triangles represent automatic $P$ picks. The location (column 32) of waveform change is indicated by a red dashed line. Potential $P$-type FZTW (see Section 3.4 for details) is marked by the orange box. (b). Along-path average slowness calculated from the data in (a). (c) Statistical result on relative slowness from data recorded by the dense array. The dots represent the mean value of relative slowness and the error bar is one standard deviation. (d) Histogram of relative slowness from data of station SGBS2 of the linear array with average relative slowness marked by the red dashed line. (e) Average relative slowness obtained from events at different locations recorded by the SGB array. The error bar is also one standard deviation.

relative slowness, we normalize the slowness at each site by the average slowness across the array. The normalization procedure is designed to mitigate effects of 3-D structure outside the FZ, and to minimize the effect of event depth.

To obtain reliable slowness values, we develop several criteria. First, we ignore automatic $P$ picks that have more than $1.0 \mathrm{~s}$ difference from the estimated $P$-wave traveltime. Second the signal-tonoise ratio, defined by the ratio between the energy observed in a $1.0 \mathrm{~s}$ time window after and before the automatic $P$ pick, is re- quired to be larger than 10. Finally, the obtained along-path average slowness values should be in a reasonable range, that is, between 0.125 and $0.25 \mathrm{~s} \mathrm{~km}^{-1}$, corresponding to an average $P$-wave velocity between 4 and $8 \mathrm{~km} \mathrm{~s}^{-1}$.

\subsubsection{Results}

The analysis is constrained to events that are close to the stations since the calculated slowness represents the along-path average. 


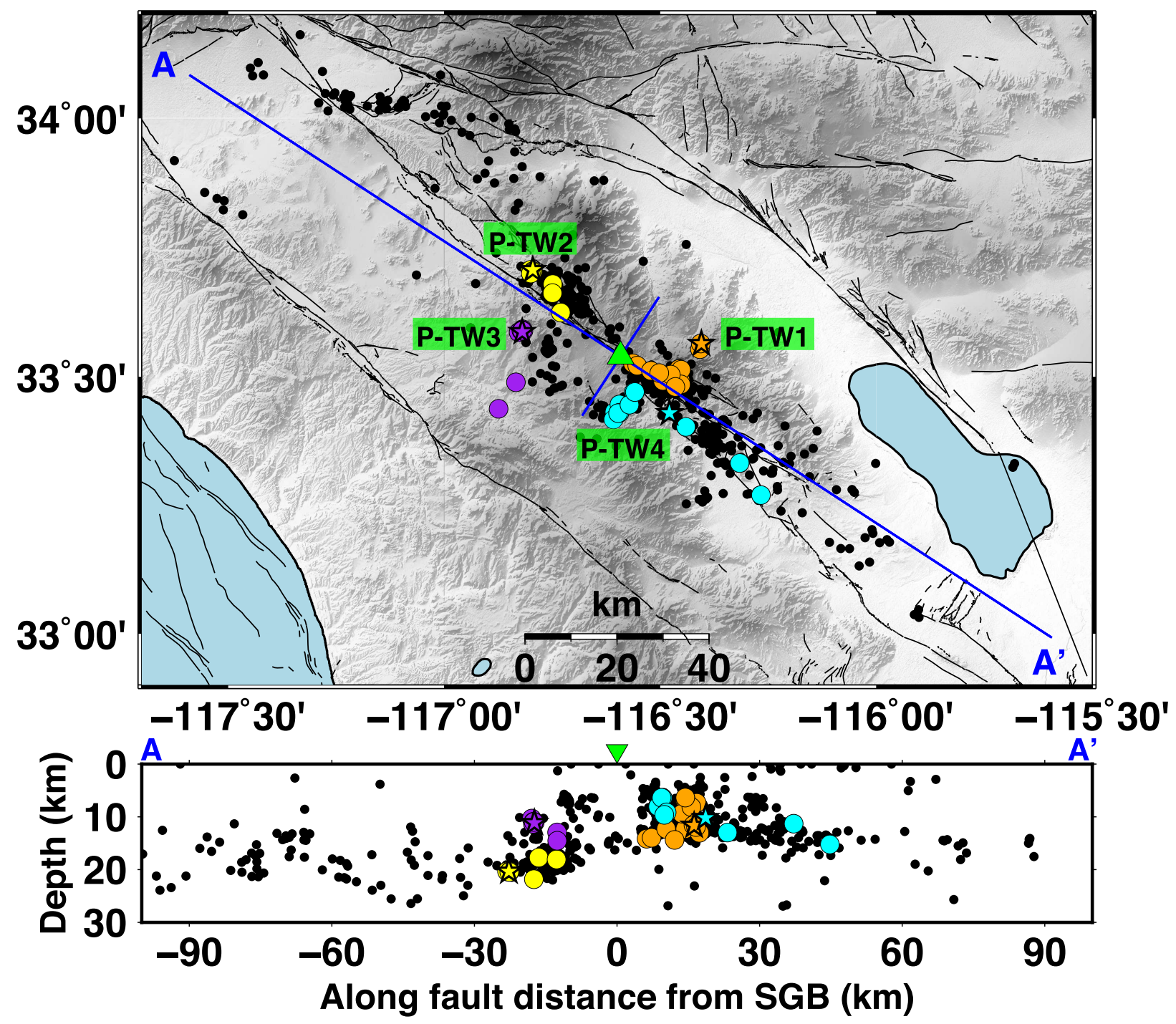

Figure 8. Location map of events (black circles) used for P-type FZTW analysis in the dense array. The two perpendicular blue lines are the same as in Fig. 3. The orange, yellow, purple and cyan circles mark events from the four quadrants that are confirmed to generate $P$-type FZTW. The stars represent four example events (P-TW1 to P-TW4). The lower panel is the depth profile projected on the cross-section $\mathrm{AA}^{\prime}$.

Specifically, we use events within the cyan box in Fig. 1(a) centred on the SGB site, extending $20 \mathrm{~km}$ in the fault-normal and $60 \mathrm{~km}$ in the along-strike directions. With this, we have $\sim 600$ and $\sim 8000$ local events for the statistical delay time analysis for data of the dense rectangular and SGB arrays, respectively. To address possible effects of event locations on the results, we also analyse separately data of the SGB array generated by events on the SW and NE side of the Clark fault. The large number of events allows us to discard records with relatively low signal-to-noise ratio, bad automatic $P$ picks, or other problems. We exclude $\sim 16$ and $\sim 80$ per cent of the lower quality records at the dense and SGB arrays, respectively, and perform delay time analyses using data of $\sim 500$ and $\sim 1500$ high-quality events at the dense and SGB arrays, respectively.

Fig. 7(a) shows waveforms for an example event recorded along row 13 of the dense rectangular array, displaying a clear change around column 32 consistent with the inferred seismogenic fault location in Section 3.1. The automatic picking algorithm gives highquality $P$ picks (Fig. 7a, red triangles), enabling the entire data set to be processed efficiently. The large-amplitude wave package following the direct $P$ wave in the records of columns 36-40 (highlighted by orange box in Fig. 7a) is a potential $P$-type FZTW, which is discussed in more detail in Section 3.4.1. The along-path average slowness (Fig. 7b) calculated from the example event is around $0.15 \mathrm{~s} \mathrm{~km}^{-1}$ and increases gradually from SW to NE. The results from all events recorded by row 13 of the dense rectangular array (Fig. 7c) also indicate that the NE side of the fault is locally slower than the SW. The distribution of relative slowness values from station SGBS2 (Fig. 7d) has well-defined mean and standard deviation values, demonstrating the reliability of the procedures and results. The relative slowness values obtained from data at the SGB array (Fig. 7e) imply again a locally slower NE side. The smaller error bar compared with results for the dense rectangular array is due to having a larger number of events. The separate analyses of events on the NE and SW sides of the fault generate similar results (Fig. 7e), leading us to conclude that the observed trends are not biased by the event locations. The delay time analyses from local events recorded at both the dense rectangular (Fig. 7c) and SGB (Fig. 7e) arrays imply a local reversal of the velocity contrast across the fault with respect to the large-scale contrast (Fig. 2), in agreement with the previous results from teleseismic events. 

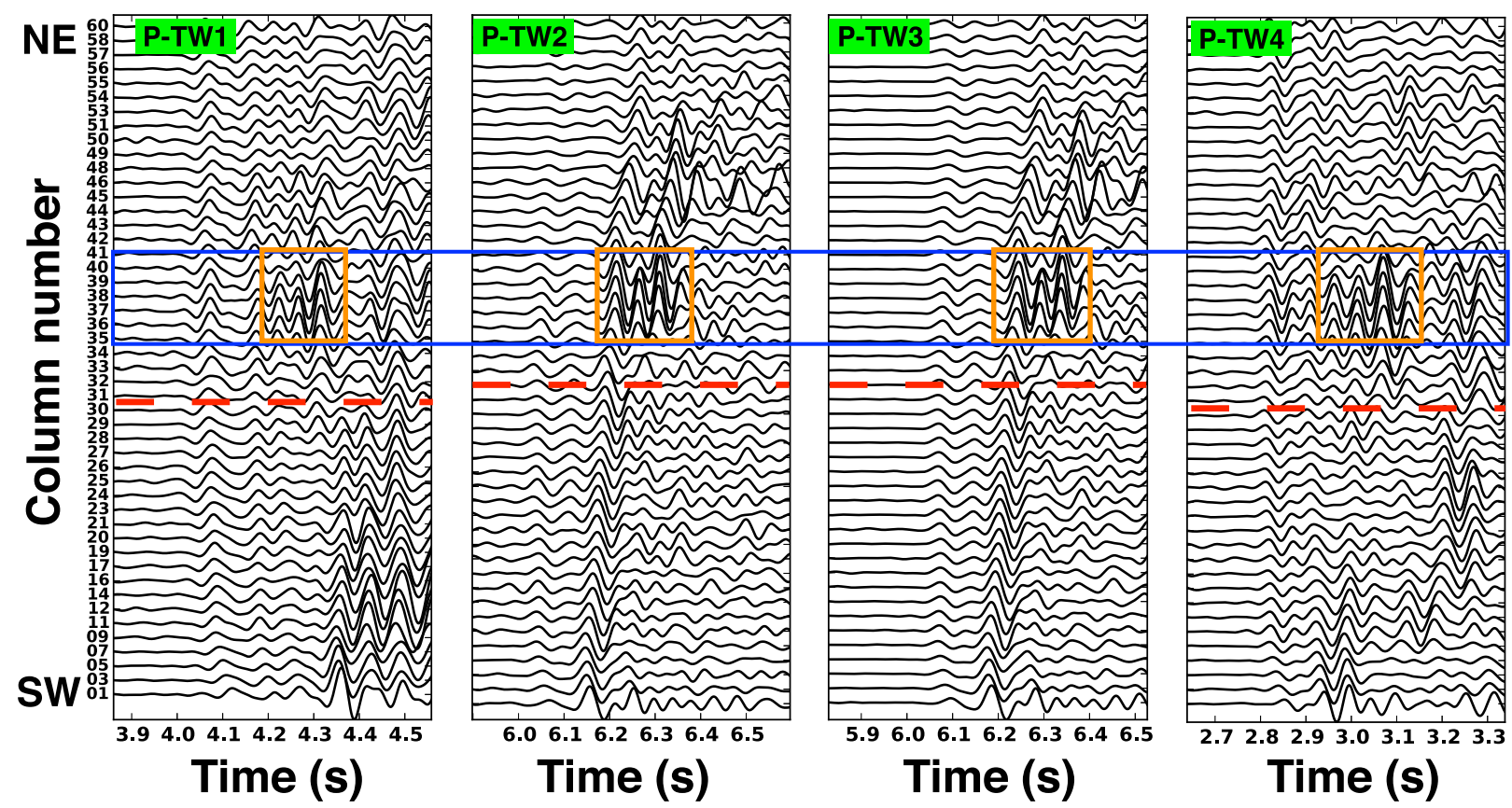

Figure 9. Waveforms $(0.5-20 \mathrm{~Hz})$ of four example events (stars in Fig. 8) recorded by row 13 of the dense array. The red dashed lines represent locations of waveform changes. The blue and orange boxes include the observed $P$-type FZTW.

\subsection{Fault zone trapped waves}

FZTW are associated with constructive interference of critically reflected phases propagating within low-velocity FZ layers that are sufficiently coherent to act as seismic waveguides (e.g. Ben-Zion \& Aki 1990; Jahnke et al. 2002). For the SH case, they are analogous to surface Love waves in a horizontally layered structure. These waves follow the $S$-body wave with relatively high amplitude and low frequencies, are somewhat dispersive, and exist predominantly in the vertical and fault parallel components of ground motion (e.g. Peng et al. 2003; Lewis \& Ben-Zion 2010). For the $P-S V$ phases, FZTW have properties similar to Rayleigh-type resonance or leaky modes (e.g. Malin et al. 2006; Gulley et al. 2017). The latter appear between the $P$ - and $S$-body waves with appreciable amplitudes on the radial and vertical components (Ellsworth \& Malin 2011). The data of the dense rectangular and SGB arrays contain clear candidate trapped waves following the $S$ - and $P$-body waves, referred to below as $S$-type and $P$-type FZTW, respectively. In the following, we first present an automatic algorithm for detection of $P$-type FZTW and summarize the detection results. Then, we present observations and modeling of $S$-type FZTW.

\subsubsection{Systematic observations of P-type FZTW}

To identify $P$-type FZTW objectively in large data sets, as done in recent analyses of $S$-type FZTW (e.g. Ross \& Ben-Zion 2015; Qiu et al. 2017), we develop an automatic detection algorithm for these phases. We apply a $0.5-20 \mathrm{~Hz}$ bandpass filter to the waveforms, compute the energy around every data point and cross-correlate waveforms of neighbouring stations. We first choose a $3.0 \mathrm{~s}$ time window starting $0.5 \mathrm{~s}$ before the median value of the automatic $P$ picks. The median $P$ arrival across the array is used for choosing the time window to avoid possible incorrect individual $P$ picks. For each sample inside the time window, we use a $0.1 \mathrm{~s}$ sliding window centred at the sample and calculate the maximum cross-correlation coefficient (CC) between all pairs of nearby stations and the energy (E) according to

$$
\begin{aligned}
& \mathrm{CC}[j, k]=\max _{n}\left(\sum_{m=-N}^{N} d_{j, k}[m] \cdot d_{j+1, k}[m+n]\right) \\
& E[j, k]=\sum_{m=1}^{N} d_{j, k}^{2}[m],
\end{aligned}
$$

where $d$ represents the data, $j$ is station index, $k$ is sample index and $N$ denotes the number of samples inside the sliding window. Largeamplitude trapped waves make the energy and cross-correlation coefficients stand out. A detection matrix (DM) for $P$-type trapped waves is obtained by multiplying the cross-correlation coefficient and energy matrices point by point. A normalized detection matrix $\left(\mathrm{DM}_{N}\right)$ is defined by

$\mathrm{DM}_{N}[j, k]=(\mathrm{DM}[j, k]-\operatorname{median}(\mathrm{DM})) / \mathrm{MAD}$.

where MAD is the median-absolute deviation defined as

$\mathrm{MAD}=\operatorname{median}(|\mathrm{DM}-\operatorname{median}(\mathrm{DM})|)$.

The matrix DM suppresses possible anomalies only in the CC or $E$, while $\mathrm{DM}_{N}$ helps to find outliers in the matrix that provide a strong indication of $P$-type FZTW. Fig. S1 in the Supporting Information shows an example of automatic detection of $P$-type trapped waves, and illustrates the waveforms and $\mathrm{DM}_{N}$ of one event with (Fig. S1a, Supporting Information) and one event without (Fig. S1b, Supporting Information) $P$-type FZTW. The waveforms in Fig. S1a in the Supporting Information contain clear $P$-type FZTW in columns 36-40, and the corresponding $\mathrm{DM}_{N}$ exhibits clear peak value $(\sim 9000)$ at these locations. On the other hand, the waveforms in Fig. S1b in the Supporting Information do not contain clear $P$-type FZTW, and the maximum $\mathrm{DM}_{N}$ value $(\sim 1200)$ is much smaller than that in Fig. S1a in the Supporting Information. 

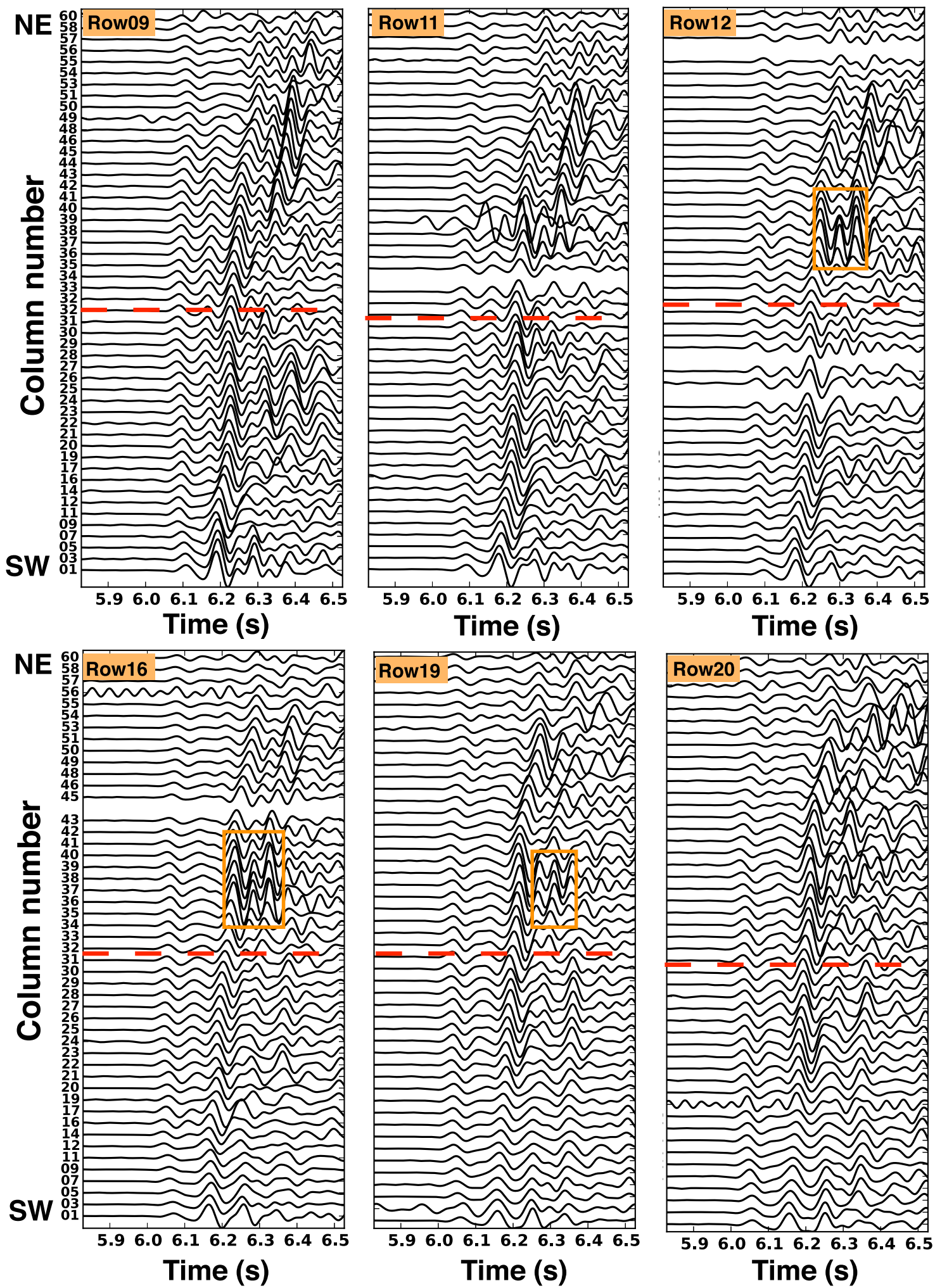

Figure 10. Waveforms $(0.5-20 \mathrm{~Hz})$ of event P-TW3 (Fig. 8) recorded by rows 09, 11, 12, 16, 19 and 20 of the dense array. The red dashed lines indicate locations of waveform changes and the orange boxes mark observed $P$-type FZTW.

Testing different thresholds for the maximum value of $\mathrm{DM}_{N}$ indicates that 4000 provides a good balance between detecting many generating events and reducing the number of false detections. In the subsequent analysis, events with a maximum $\mathrm{DM}_{N}$ value above
4000 are flagged as potential candidates. Sensors that have $\mathrm{DM}_{N}$ values larger than 40 per cent of the peak $\mathrm{DM}_{N}$, and with separation between potential $P$-type FZTW and median $P$ arrival by at least $0.1 \mathrm{~s}$, are identified as recording $P$-type trapped waves. 


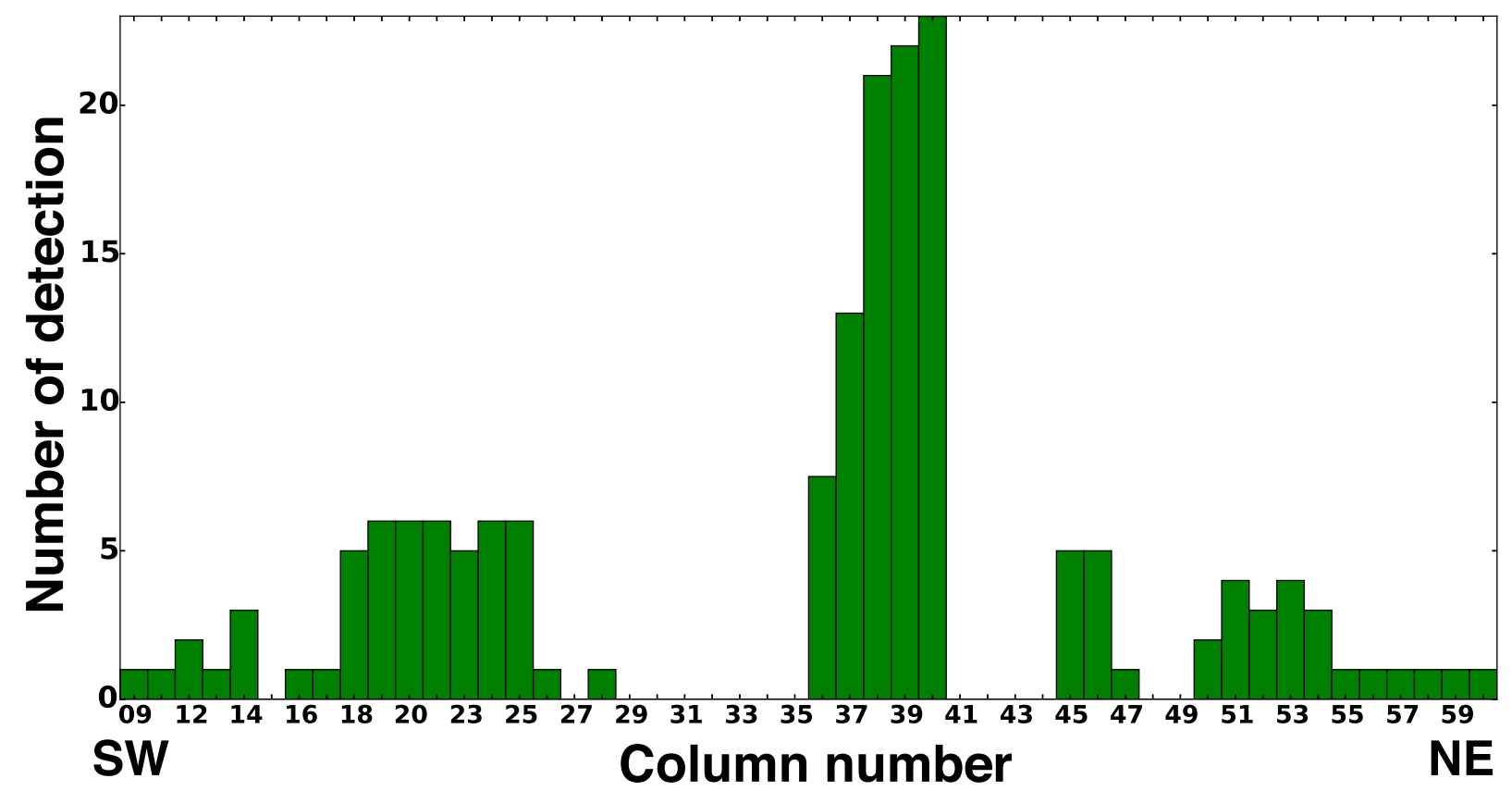

Figure 11. Histogram of automatic $P$-type FZTW detection results at different stations of row 13.

We run the automatic detection algorithm for all the events in Fig. 8 and visually check the flagged events to eliminate false detections. The remaining events are spread in all four quadrants around the SGB site (Fig. 8) over the approximate depth range 10$20 \mathrm{~km}$. Fig. 9 presents examples of seismograms from four events (one in each quadrant) marked as stars in Fig. 8 that generate $P$-type FZTW in columns $36-40$ of row 13 of the dense array. The repeating occurrence of these wave packets at similar sensor locations, independent of the event locations, implies that they are resonance modes associated with the FZ structure. The generation of FZTW from events at considerable distances from the fault implies a relatively shallow trapping structure (Ben-Zion et al. 2003; Fohrmann et al. 2004). This is because a deep low-velocity FZ layer would reflect most of the energy from off-fault events, and generate trapped waves only from events very close to the fault (e.g. Ben-Zion 1998; Jahnke et al. 2002).

To clarify the along-strike extent of the trapping structure, we plot the waveforms generated by event P-TW3 recorded by several other rows (Fig. 10). The results from this and other examples show $P$-type FZTW in columns $36-40$ of rows 12 and 19 , while in other rows there are no such waves after the direct $P$ arrival. Ben-Zion et al. (2015) presented similar observations on the spatial extent of the trapping structure based on Betsy gunshot data recorded by the dense rectangular array. Fig. 11 summarizes the automatic detection of $P$-type FZTW from all examined events. The detections at columns 36-40 stand out and the corresponding waveforms are consistent with the results shown in Fig. 9. The false detections near columns $10-25$ and $45-55$ are associated with amplified motions in other local low-velocity zones in the area (Ben-Zion et al. 2015; Hillers et al. 2016; Roux et al. 2016).

\subsubsection{Analysis of S-type FZTW}

To study $S$-type trapped waves, we apply different methods to data recorded by the dense and SGB arrays. For the dense array, which only has vertical-component data, we stack the waveforms from events deeper than $15 \mathrm{~km}$ recorded by multiple rows that have similar elevation (i.e. rows 12-18, green dots in Fig. 1c). This reduces small-scale local variations due to uncorrelated noise and scattering, and enhances common resonance modes associated with FZTW with relatively large amplitude and small time offset. For the SGB array, we first rotate the recordings to the fault-parallel component to maximize the signal strength. Next, we run the automatic $S$-type FZTW detector of Ross \& Ben-Zion (2015) and check the detected events visually to eliminate incorrect detections. Detected highquality $S$-type trapped waves are inverted for properties of the FZ waveguide using a genetic inversion algorithm with a forward kernel based on the 2-D analytic solution of Ben-Zion \& Aki (1990) and Ben-Zion (1998). We assume a simple model with a low-velocity FZ layer in a half-space (e.g. Qiu et al. 2017), and invert for the following six parameters: shear wave velocity, $Q$ value and width of the FZ layer, shear wave velocity of the host rock, distance of the SW edge of the FZ layer from sensor SGBS3, and propagation distance inside the FZ. The inversion algorithm explores systematically the trade-offs among these six parameters (Ben-Zion 1998) and finds the best model that explains the observed trapped waves. The best model should be close to the most likely model associated with peaks of the probability density distributions of the parameter space explored by the inversion algorithm (Ben-Zion et al. 2003).

Fig. 12 shows the events examined for $S$-type FZTW and detection results for the dense and SGB arrays. For data recorded by the dense array, we search over all events deeper than $15 \mathrm{~km}$ (purple diamonds in Fig. 12) during the dense array deployment and stack the waveforms of rows 12-18 (green symbols in Fig. 1c). As with the $P$-type FZTW, the detections are spread in a broad region around the fault implying a relatively shallow waveguide. Fig. 13 presents stacked waveforms for example event S-TW1. The stacked data show clear $S$-type FZTW along with $P$-type FZTW at the previously inferred core damage zone (columns 36-40). For the SGB array, detected $S$-type FZTW by the automatic algorithm are observed at sensors SGBF0-SGBN2 that overlap with columns 36-40 


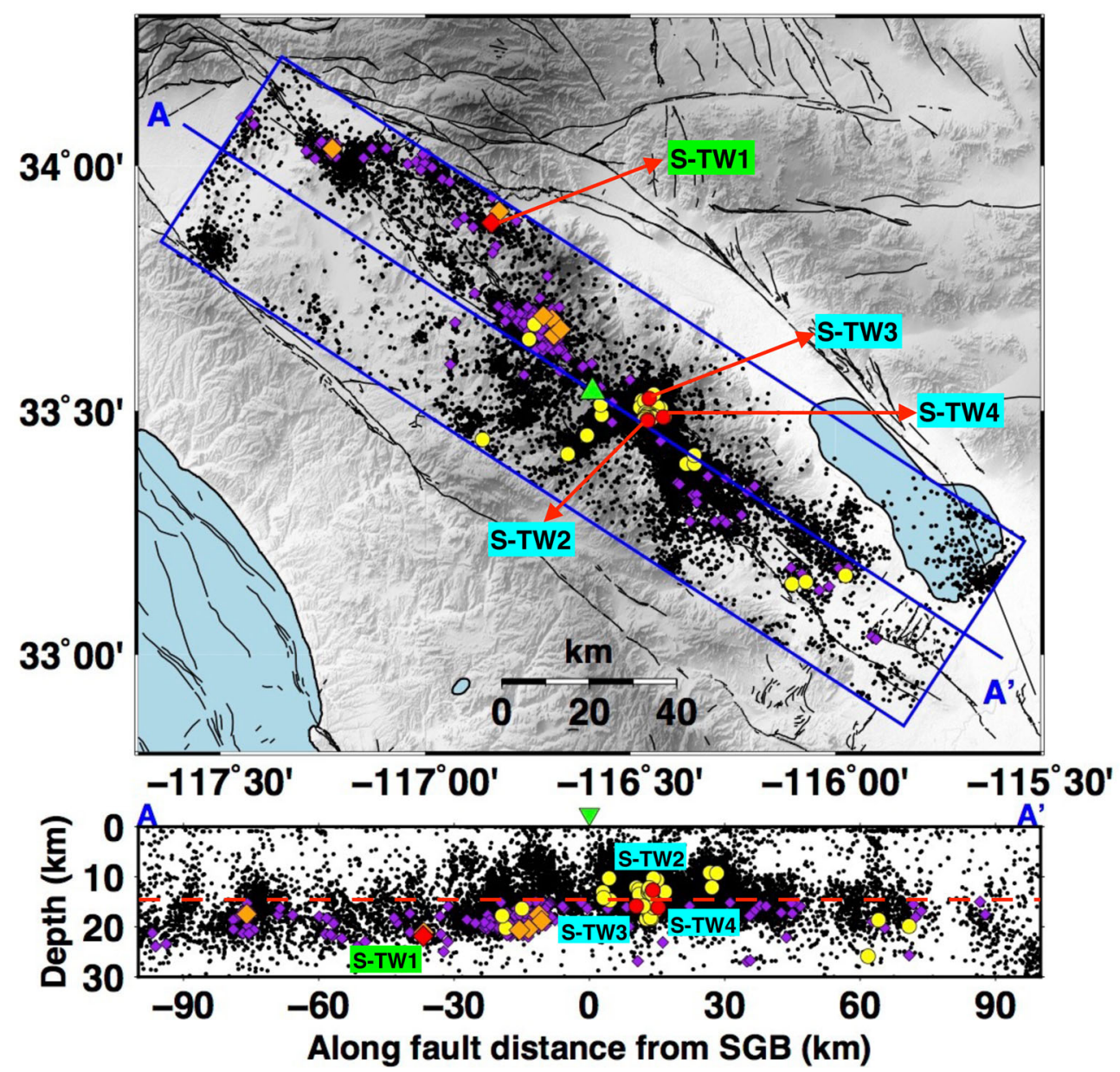

Figure 12. Location map of events for $S$-type FZTW study. The large blue box and line AA' are the same as in Fig. 1(a). Purple diamonds and black dots mark events used in data of dense and linear SGB arrays, respectively. Orange diamonds and yellow circles represent events that are confirmed to generate $S$-type FZTW in the dense and SGB arrays, respectively. Waveforms from S-TW1 (red diamond) and S-TW2 (red circle) are shown and modeled in Figs 13 and 14, respectively. Inversion results of S-TW3 and S-TW4 (red circles) are shown in Figs S2 and S3 in the Supporting Information. The lower panel is depth profile projected to the cross-section $\mathrm{AA}^{\prime}$ with red dashed line marking a depth of $15 \mathrm{~km}$.

of row 13 of the dense array. This consistently suggests a trapping structure beneath SGBF0-SGBN2. Fig. 14 presents inversion results of $S$-type FZTW generated by example event S-TW2. The synthetic waveforms in Fig. 14a (red lines) are generated by model parameters producing the highest fitness values (Fig. 14b, solid circles) in 10000 inversion iterations. The fitness is defined as $(1+$ C) $/ 2$ where $C$ is the cross-correlation coefficient between observed and synthetic waveforms. Summing the fitness values of the final 2000 inversion iterations (green dots in Fig. 14b) and normalizing the results to have unit sums give probability density functions for the various model parameters (curves in Fig. 14b). The most likely parameters of the trapping structure (peaks of curves in Fig. 14b) are width of $\sim 70 \mathrm{~m}, S$-wave velocity reduction of $\sim 60$ per cent and $Q$ value of $\sim 60$. The most likely propagation distance within the trapping structure is $\sim 2 \mathrm{~km}$, confirming the presence of a shallow trapping structure at the study site (Section 3.4.1). Modeling additional high-quality $S$-type FZTW recorded by the SGB array lead to similar results (Figs S2 and S3, Supporting Information).

\section{DISCUSSION AND CONCLUSIONS}

We image the internal structure of the SJFZ at the Sage Brush site in the trifurcation area, using data recorded by a dense rectangu- lar array with 1108 vertical-component sensors around the Clark branch of the SJFZ and a linear array of six 3-component sensors. The two arrays provide complementary recordings that allow us to extract important information on key mechanical components of the FZ structure. The fine-gridded areal coverage of the dense array compensates for the shorter recording duration of one month and vertical-component data, while the shorter aperture linear array provides three years of three-component data. The data are examined for clear localized changes of waveforms that indicate a transition between different crustal blocks, delay times of $P$ waves that provide information on variations of slowness in the study area and $P$ - and $S$-types FZTW that propagate within a seismic waveguide in a portion of the damage structure.

Fig. 15 summarizes the local velocity structure inferred from the performed analyses. The location of the main Clark fault at depth is inferred to be below the sensors marked by yellow. This location is found by examining waveform changes in the fault-normal and fault-parallel directions and observing systematically (Figs 4 and 5) different phases across the marked zone. The delay time analysis of teleseismic and local earthquakes (Figs 6 and 7) indicate higher slowness to the NE of the main Clark fault. Examination of recorded seismograms with automatic detection algorithms and visual inspection show regular occurrence of $P$ - and $S$-types FZTW 


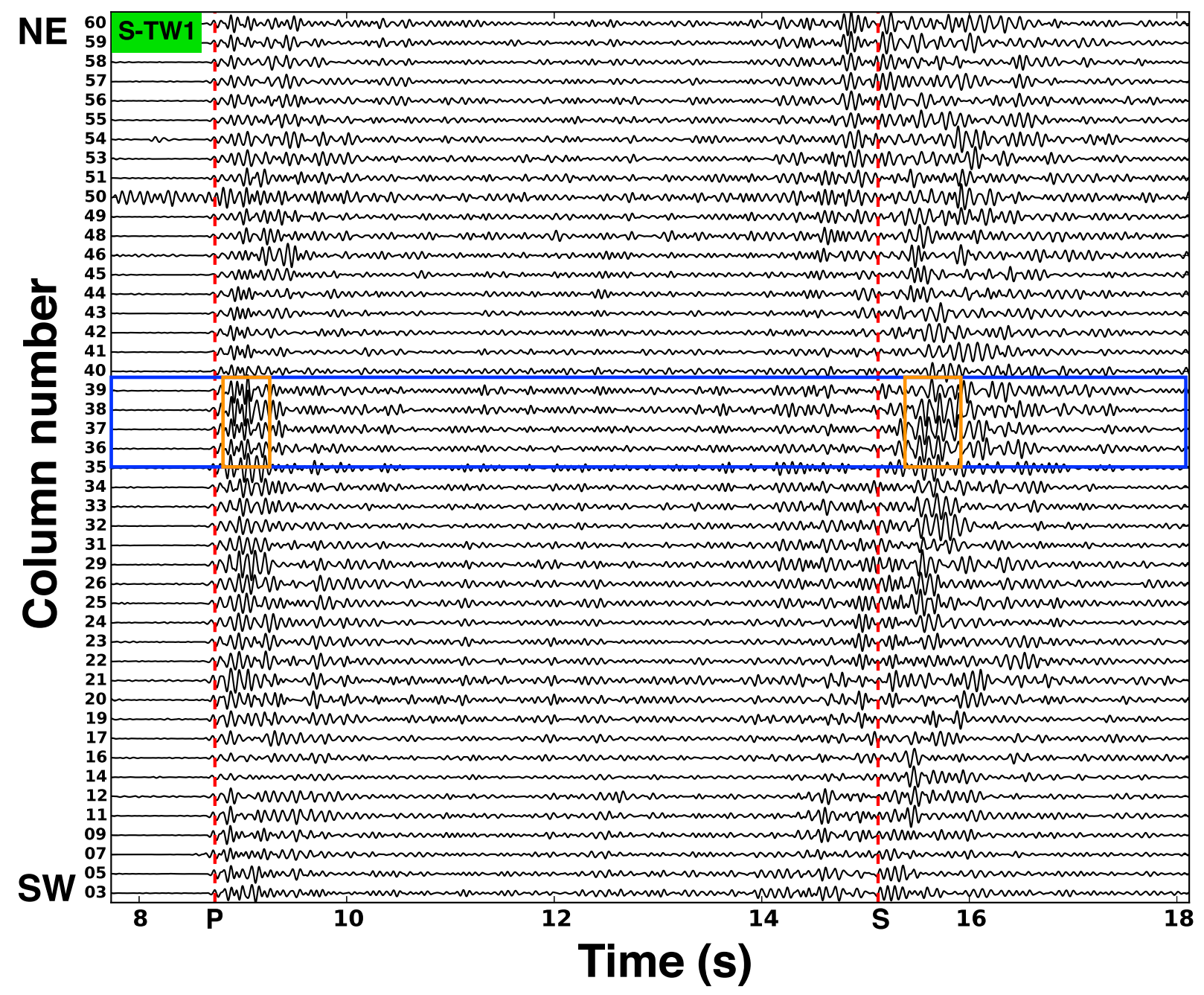

Figure 13. Stacked waveforms at rows 12-18 generated by event S-TW1 (Fig. 12, red diamond). Direct $P$ and $S$ waves are labeled by red dashed lines and orange boxes mark $P$ - and $S$-types FZTW.

in a zone on the NE side of the main Clark fault denoted by red sensors. This region is associated with columns $36-40$ of the dense array along with stations SGBF0-SGBN2 of the linear array, and is approximately bounded to the NE with another mapped surface trace of the fault. These results are consistent with observations of FZTW generated by Betsy gunshots (Ben-Zion et al. 2015) and detailed noise-based imaging of a significant low-velocity zone on the NE side of the main Clark fault (Roux et al. 2016; Hillers et al. 2016).

Earthquake- and noise-based tomographic models show that the SJFZ in the study area separates a crustal block with higher seismic velocity to the NE from a block with lower velocity to the SW (Allam \& Ben-Zion 2012; Allam et al. 2014; Zigone et al. 2015). Theoretical studies indicate that bimaterial ruptures on a right-lateral fault associated with the imaged large-scale velocity contrast would tend to propagate to the NW (e.g. Andrews \& Ben-Zion 1997; Shi \& Ben-Zion 2006; Brietzke et al. 2009). Repeating occurrence of large bimaterial ruptures to the NW is expected to generate significantly more shallow damage on the NE side with faster velocity at depth (Ben-Zion \& Shi 2005; Xu et al. 2012), leading to a local reversal of the shallow velocity contrast in the immediate vicinity of the Clark fault as summarized in Fig. 15.
Geological mapping shows slivers of gneisses in the area predominantly NE of the fault (Sharp 1967; Gutierrez et al. 2010; Wade et al. 2017). These rocks have lower than average velocities in the region (Allam \& Ben-Zion 2012; Share et al. 2017) and may contribute to the local reversal in the velocity contrast. However, comparison of the surface geology with the seismic imaging results of Roux et al. (2016) suggests that these rocks may exist only near the surface and have small effect on the asymmetric damage structure that extends to a depth of about $2 \mathrm{~km}$ (Section 3.4.2). Similar damagerelated local reversals of the shallow velocity contrast across the Clark fault were documented at sites JF and BB (Qiu et al. 2017; Share et al. 2017) several tens of kilometres to the SE and NW from the SGB site, respectively (Fig. 2). The discussed observational and theoretical results suggest consistently preferred propagation of earthquake ruptures in the central SJFZ to the NW. This is in agreement with observed directivity of small to moderate events (Kurzon et al. 2014; Ross \& Ben-Zion 2016), along-strike asymmetry of aftershocks (Zaliapin \& Ben-Zion 2011) and locations of reversedpolarity secondary deformation structures in the region (Ben-Zion et al. 2012).

Palaeoseismic and historic records indicate that the SJFZ is capable of large $\left(M_{\mathrm{w}}>7.0\right)$ earthquakes (e.g. Petersen \& 
(a)

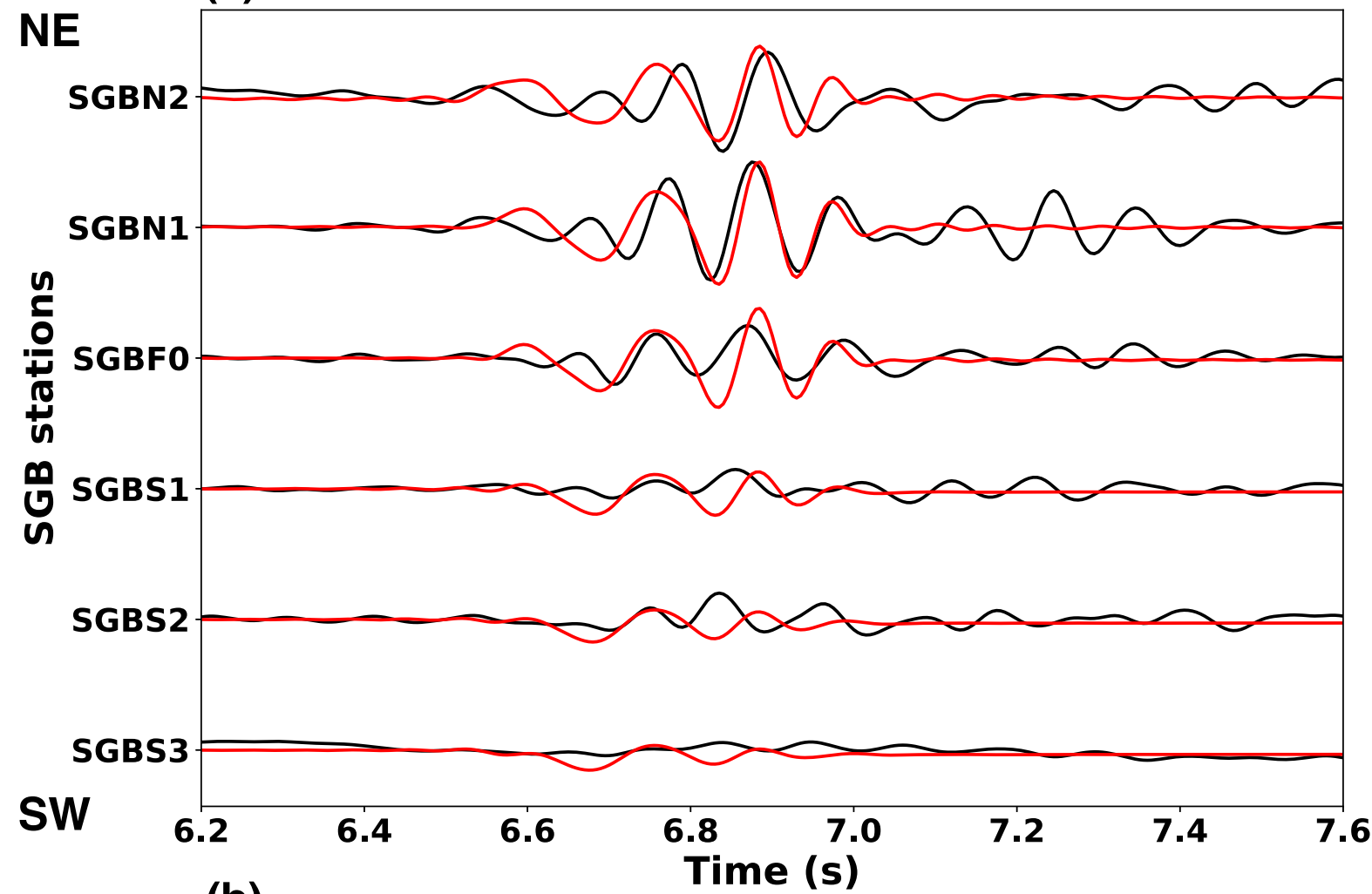

(b)
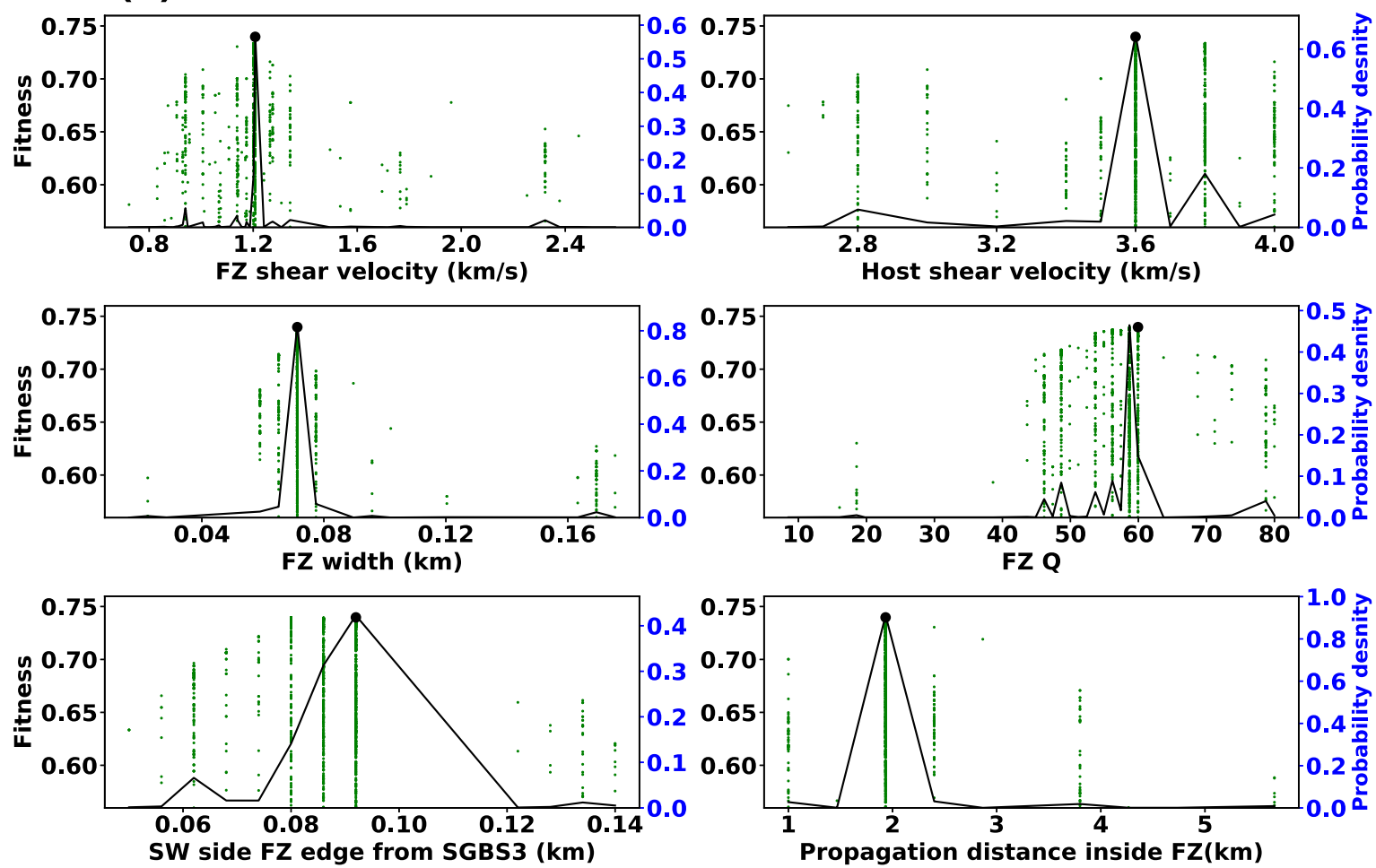

Figure 14. Inversion results of waveforms generated by event S-TW2 (Fig. 12, red diamond). (a) Comparison between observed (black) and synthetic (red) seismograms. (b) Parameter-space results from last 10 inversion generations. Green dots represent the tested model parameters and black circles mark the best-fitting parameters used to generate the synthetic waveforms in (a). The black curves give probability density functions of the model parameters. 


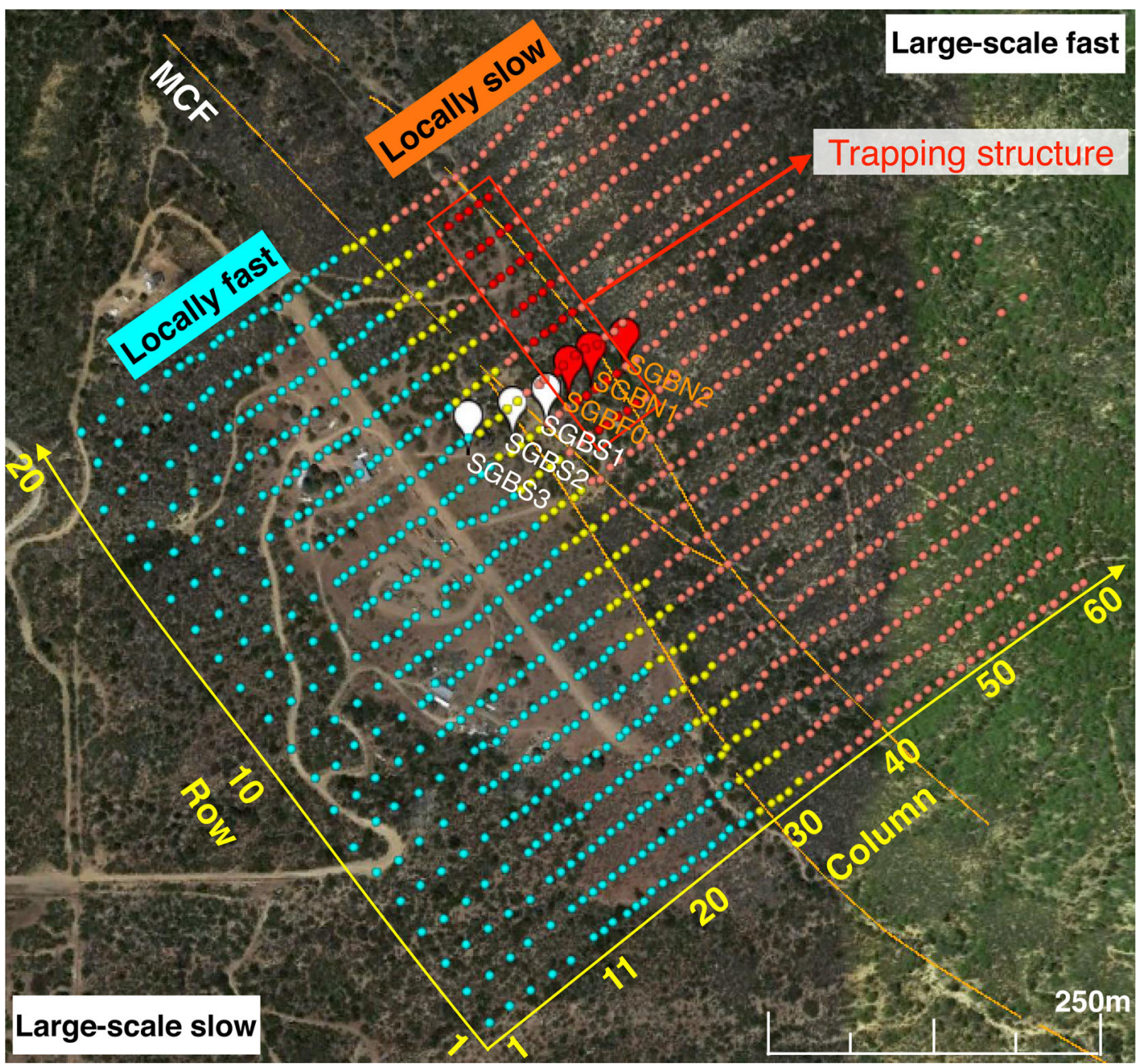

Figure 15. A simplified velocity model of the SGB site. Circles and balloons represent stations of the dense and linear SGB arrays, respectively. The labeled rows and columns are the same as in Fig. 1(a). Orange lines are fault surface traces. Yellow sensors mark the location of the main seismogenic fault inferred from waveform changes. A low-velocity zone that generates $P$ - and $S$-types FZTW is beneath the stations in red. The main Clark fault (MCF) separates locally faster material on the SW (cyan) from locally slower rocks on the NE (pink). The local velocity contrast across the MCF is reversed with respect to the large-scale structure.

Wesnousky 1994; Rockwell et al. 2015), and has the potential to rupture along nearly the entire length of the FZ in a single event (e.g. Salisbury et al. 2012; Onderdonk et al. 2013). The last throughgoing event probably occurred in 1800 (Salisbury et al. 2012) and the average recurrence time for such events is estimated at $257 \pm$ $79 \mathrm{yr}$ (Rockwell et al. 2015). The SJFZ poses a significant current seismic hazard to large urban areas in southern California. Propagation direction of a large SJFZ earthquake to the NW, consistent with the statistical tendencies implied by the discussed results, would amplify the seismic shaking in Riverside and other communities in that direction.

\section{ACK NOWLEDGEMENTS}

We are grateful to Bud Wellman for allowing us to deploy the instruments on his property. The study was supported by the $\mathrm{Na}$ tional Science Foundation (grant EAR-1620601) and the Department of Energy (awards DE-SC0016520 and DE-SC0016527). The seismic instruments of the dense rectangular array were provided by Nodal Seismic with help from Dan Hollisand and Mitchell Barklage. The seismic instruments of the linear array were provided by the Incorporated Research Institutions for Seismology (IRIS) through the PASSCAL Instrument Center at New Mexico Tech. The facilities of the IRIS Consortium are supported by the National Science Foundation under Cooperative Agreement EAR-1261681 and the DOE National Nuclear Security Administration. The manuscript benefitted from comments of two anonymous referees.

\section{REFERENCES}

Allam, A.A. \& Ben-Zion, Y., 2012. Seismic velocity structures in the Southern California plate-boundary environment from double-difference tomography, Geophys. J. Int., 190(2), 1181-1196.

Allam, A.A., Ben-Zion, Y., Kurzon, I. \& Vernon, F., 2014. Seismic velocity structure in the Hot Springs and Trifurcation areas of the San Jacinto fault zone, California, from double-difference tomography, Geophys. J. Int., 198(2), 978-999.

Andrews, D.J. \& Ben-Zion, Y.1997. Wrinkle-like slip pulse on a fault between different materials, J. geophys. Res., 102(B1), 553-571.

Ben-Zion, Y., 1989. The response of two joined quarter spaces to SH line sources located at the material discontinuity interface, Geophys. J. Int., 98(2), 213-222. 
Ben-Zion, Y., 1998. Properties of seismic fault zone waves and their utility for imaging low-velocity structures, J. geophys. Res., 103(B6), $12567-$ 12585 .

Ben-Zion, Y., 2001. Dynamic ruptures in recent models of earthquake faults, J. Mech. Phys. Solids, 49(9), 2209-2244.

Ben-Zion, Y. \& Aki, K., 1990. Seismic radiation from an SH line source in a laterally heterogeneous planar fault zone, Bull. seism. Soc. Am., 80(4), 971-994.

Ben-Zion, Y. \& Sammis, C.G., 2003. Characterization of fault zones. In Seismic Motion, Lithospheric Structures, Earthquake and Volcanic Sources: The Keiiti Aki Volume, pp. 677-715, Birkhäuser Basel.

Ben-Zion, Y. et al., 2003. A shallow fault-zone structure illuminated by trapped waves in the Karadere-Duzce branch of the North Anatolian Fault, western Turkey, Geophys. J. Int., 152(3), 699717.

Ben-Zion, Y. \& Shi, Z., 2005. Dynamic rupture on a material interface with spontaneous generation of plastic strain in the bulk, Earth planet. Sci. Lett., 236(1-2), 486-496.

Ben-Zion, Y., Rockwell, T.K., Shi, Z. \& Xu, S., 2012. Reversed-polarity secondary deformation structures near fault stepovers, J. appl. Mech., 79(3), 031025, doi:10.1115/1.4006154.

Ben-Zion, Y. et al., 2015. Basic data features and results from a spatially dense seismic array on the San Jacinto fault zone, Geophys. J. Int., 202(1), 370-380.

Brietzke, G.B. \& Ben-Zion, Y., 2006. Examining tendencies of in-plane rupture to migrate to material interfaces, Geophys. J. Int., 167(2), 807819.

Brietzke, G.B., Cochard, A. \& Igel, H., 2009. Importance of bimaterial interfaces for earthquake dynamics and strong ground motion, Geophys. J. Int., 178(2), 921-938.

Crotwell, H.P., Owens, T.J. \& Ritsema, J., 1999. The TauP Toolkit: flexible seismic travel-time and ray-path utilities, Seismol. Res. Lett., 70(2), 154160.

Dor, O., Rockwell, T.K. \& Ben-Zion, Y., 2006. Geological observations of damage asymmetry in the structure of the San Jacinto, San Andreas and Punchbowl faults in Southern California: a possible indicator for preferred rupture propagation direction, Pure appl. geophys., 163(2-3), 301-349.

Ellsworth, W.L. \& Malin, P.E., 2011. Deep rock damage in the San Andreas Fault revealed by P- and S-type fault-zone-guided waves, Geol. Soc. Lond., Spec. Publ., 359(1), 39-53.

Fohrmann, M., Igel, H., Jahnke, G. \& Ben-Zion, Y., 2004. Guided waves from sources outside faults: an indication for shallow fault zone structure? Pure appl. geophys., 161(11), 2125-2137.

Gulley, A., Kaipio, J.P., Eccles, J.D. \& Malin, P.E., 2017. A numerical approach for modelling fault-zone trapped waves, Geophys. J. Int, 201(2), pp. 919-930.

Gutierrez, C., Bryant, W., Saucedo, W.G. \& Wills, C., 2010. Geologic Map of California, California Geological Survey.

Hauksson, E., Yang, W. \& Shearer, P.M., 2012. Waveform relocated earthquake catalog for southern California (1981 to June 2011), Bull. seism. Soc. Am., 102(5), 2239-2244.

Hillers, G., Roux, P., Campillo, M. \& Ben-Zion, Y. 2016. Focal spot imaging based on zero lag cross-correlation amplitude fields: application to dense array data at the San Jacinto fault zone, J. geophys. Res., 121(11), 80488067.

Jahnke, G., Igel, H. \& Ben-Zion, Y., 2002. Three-dimensional calculations of fault-zone-guided waves in various irregular structures, Geophys. J. Int., 151(2), 416-426.

Kurzon, I., Vernon, F.L., Ben-Zion, Y. \& Atkinson, G., 2014. Ground motion prediction equations in the San Jacinto fault zone: significant effects of rupture directivity and fault zone amplification, Pure appl. geophys., 171(11), 3045-3081.

Lewis, M.A., Peng, Z., Ben-Zion, Y. \& Vernon, F.L., 2005. Shallow seismic trapping structure in the San Jacinto fault zone near Anza, California, Geophys. J. Int., 162(3), 867-881.

Lewis, M.A. \& Ben-Zion, Y., 2010. Diversity of fault zone damage and trapping structures in the Parkfield section of the San Andreas Fault from comprehensive analysis of near fault seismograms, Geophys. J. Int., 183(3), 1579-1595.

Li, Z., Peng, Z., Ben, Zion, Y. \& Vernon, F.L., 2015. Spatial variations of shear wave anisotropy near the San Jacinto Fault Zone in Southern California, J. geophys. Res., 120(12), 8334-8347.

Malin, P., Shalev, E., Balven, H., Lewis \& Kenedi, C., 2006. Structure of the San Andreas Fault at SAFOD from P-wave tomography and fault-guided wave mapping, Geophys. Res. Lett., 33(13), doi:10.1029/2006GL025973.

Onderdonk, N.W., Rockwell, T.K., McGill, S.F. \& Marliyani, G.I., 2013. Evidence for seven surface ruptures in the past 1600 years on the Claremont Fault at Mystic Lake, Northern San Jacinto Fault Zone, California, Bull. seism. Soc. Am., 103(1), 519-541.

Ozakin, Y., Ben, Zion, Y., Aktar, M., Karabulut, H. \& Peng, Z., 2012. Velocity contrast across the 1944 rupture zone of the North Anatolian fault east of Ismetpasa from analysis of teleseismic arrivals, Geophys. Res. Lett., 39(8), doi:10.1029/2012GL051426.

Peng, Z., Ben-Zion, Y., Michael, A.J. \& Zhu, L., 2003. Quantitative analysis of seismic fault zone waves in the rupture zone of the 1992 Landers, California, earthquake: evidence for a shallow trapping structure, Geophys. J. Int., 155(3), 1021-1041.

Petersen, M.D. \& Wesnousky, S.G., 1994. Fault slip rates and earthquake histories for active faults in southern California, Bull. seism. Soc. Am., 84(5), 1608-1649.

Qiu, H., Ben-Zion, Y., Ross, Z.E., Share, P.E. \& Vernon, F.L., 2017. Internal structure of the San Jacinto fault zone at Jackass Flat from data recorded by a dense linear array, Geophys. J. Int., 209(3), 1369-1388.

Rockwell, T.K., Dawson, T.E., Ben-Horin, J.Y. \& Seitz, G., 2015. A 21event, 4,000-year history of surface ruptures in the Anza seismic gap, San Jacinto Fault, and implications for long-term earthquake production on a major plate boundary fault, Pure appl. geophys., 172(5), 1143-1165.

Ross, Z.E. \& Ben-Zion, Y., 2014. Automatic picking of direct P, S seismic phases and fault zone head waves, Geophys. J. Int., 199(1), 368-381.

Ross, Z.E. \& Ben-Zion, Y., 2015. An algorithm for automated identification of fault zone trapped waves, Geophys. J. Int., 202(2), 933-942.

Ross, Z.E., Ben \& Zion, Y., 2016. Toward reliable automated estimates of earthquake source properties from body wave spectra, J. geophys. Res., 121(6), 4390-4407.

Ross, Z.E., White, M.C., Vernon, F.L. \& Ben-Zion, Y., 2016. An improved algorithm for real-time S-wave picking with application to the (Augmented) ANZA Network in Southern California, Bull. seism. Soc. Am., 106(5), 2013-2022.

Ross, Z.E., Hauksson, E. \& Ben-Zion, Y., 2017. Abundant off-fault seismicity and orthogonal structures in the San Jacinto fault zone, $S c i$. $A d v$, 3(3), e1601946, doi:10.1126/sciadv.1601946, 2017.

Roux, P., Moreau, L., Lecointre, A., Hillers, G., Campillo, M., Ben-Zion, Y., Zigone, D. \& Vernon, F., 2016. A methodological approach towards high-resolution surface wave imaging of the San Jacinto Fault Zone using ambient-noise recordings at a spatially dense array, Geophys. J. Int., 206(2), 980-992.

Salisbury, J.B., Rockwell, T.K., Middleton, T.J. \& Hudnut, K.W., 2012. LiDAR and field observations of slip distribution for the most recent surface ruptures along the central San Jacinto fault, Bull. seism. Soc. Am., 102(2), 598-619.

SCEDC, 2013. Southern California Earthquake Center, Caltech Dataset, doi:10.7909/C3WD3xH.

Shi, Z. \& Ben-Zion, Y., 2006. Dynamic rupture on a bimaterial interface governed by slip-weakening friction, Geophys. J. Int., 165(2), 469-484.

Share, P.-E., Ben-Zion, Y., Ross, Z., Qiu, H. \& Vernon, F., 2017. Internal structure of the San Jacinto fault zone at Blackburn Saddle from seismic data of a linear array, Geophys. J. Int., 2, doi:10.1093/gji/ggx191.

Sharp, R.V., 1967. San Jacinto Fault Zone in the Peninsular Ranges of Southern California, Bull. geol. Soc. Am., 78(6), 819-832.

Vernon, F. \& Ben-Zion, Y.2010. San Jacinto Fault Zone Experiment. International Federation of Digital Seismograph Networks. Other/Seismic Network, doi:10.7914/SN/YN_2010.

Wade, A., Arrowsmith, J.R., Donnellan, A., Vernon, F. \& Ben-Zion, Y., 2017. Dekameter-scale geologic structure validation of shallow seismic properties along the San Jacinto fault at Sage Brush Flat, Anza, 
California, in Abstract of the SCEC Annual Meeting, Palm Springs, CA, 10-13 September.

Xu, S., Ben-Zion, Y. \& Ampuero, J.P., 2012. Properties of inelastic yielding zones generated by in-plane dynamic ruptures-II. Detailed parameterspace study, Geophys. J. Int., 191(3), 1343-1360.

Xu, S. \& Ben-Zion, Y., 2017. Theoretical constraints on dynamic pulverization of fault zone rocks, Geophys. J. Int., 209(1), 282-296.

Yang, H., Li, Z., Peng, Z., Ben, Zion, Y. \& Vernon, F., 2014. Low-velocity zones along the San Jacinto Fault, Southern California, from body waves recorded in dense linear arrays, J. geophys. Res., 119(12), 8976-8990.

Zaliapin, I. \& Ben-Zion, Y., 2011. Asymmetric distribution of aftershocks on large faults in California, Geophys. J. Int., 185(3), 1288-1304.

Zigone, D., Ben-Zion, Y., Campillo, M. \& Roux, P., 2015. Seismic tomography of the Southern California plate boundary region from noise-based Rayleigh and Love waves, Pure appl. geophys., 172(5), 1007-1032.

\section{SUPPORTING INFORMATION}

Supplementary data are available at GJI online.

Figure S1. (a) Left: waveforms $(0.5-20 \mathrm{~Hz})$ of an event recorded by row 13 . The red dashed lines indicate the $3.0 \mathrm{~s}$ time window in which $\mathrm{DM}_{N}$ is calculated. The orange box includes the $P$-type FZTW. Right: corresponding $\mathrm{DM}_{N}$ values represented by colour. The white dashed line is the median of automatic $P$ picks in row 13. The orange box indicates the location where the $P$-type FZTW are detected. (b) Same as (a) for an event without $P$-type FZTW.

Figure S2. FZTW inversion results of waveforms generated by event S-TW3 (location marked in Fig. 12). The layout is the same as Fig. 14.

Figure S3. FZTW inversion results of waveforms generated by event S-TW4 (location marked in Fig. 12). The layout is the same as Fig. 14.

Please note: Oxford University Press are not responsible for the content or functionality of any supporting materials supplied by the authors. Any queries (other than missing material) should be directed to the corresponding author for the paper. 